\title{
Elucidation of one step synthesis of PEGylated CuFe bimetallic nanoparticles. Antimicrobial activity of CuFe@ PEG vs Cu@ PEG
}

O. Antonoglou, ${ }^{\mathrm{a}}$ K. Giannousi, ${ }^{\mathrm{a}}$ J. Arvanitidis, ${ }^{\mathrm{c}}$ S. Mourdikoudis,,${ }^{\mathrm{d} e \mathrm{e}}$ A. Pantazaki ${ }^{\mathrm{b}^{*}}$ \& C. Dendrinou-Samara ${ }^{a^{*}}$

${ }^{a}$ Lab of Inorganic Chemistry, Department of Chemistry, Aristotle University of Thessaloniki, 54124 Thessaloniki, Greece; ${ }^{b}$ Lab of Biochemistry, Department of Chemistry, Aristotle University of Thessaloniki, 'Department of Physics, Aristotle University of Thessaloniki, Thessaloniki, Greece; ${ }^{\mathrm{d}}$ UCL Healthcare Biomagnetic and Nanomaterials Laboratories, London, UK; e Biophysics Group, Department of Physics and Astronomy, University College London (UCL), London, UK.

* Corresponding author, C. Dendrinou-Samara Email: samkat@chem.auth.gr, natasa@chem.auth.gr Tel: +30-2310-99-7876

Keywords: Bimetallic Nanoparticles, CuFe Nanoparticles, PEGylated, Antimicrobial Activity, Reactive Oxygen Species. 


\begin{abstract}
There is a growing field of research on the physicochemical properties of bimetallic nanoparticles (BMNPs) and their potential use in different applications. Meanwhile, their antimicrobial activity is scarcely reported, although BMNPs can potentially achieve unique chemical transformations and synergetic effects can be presented. Towards this direction a reproducible simple hybrid polyol process under moderate temperature solvothermal conditions has been applied for the isolation of non oxide contaminated bimetallic CuFe nanoparticles (NPs). 1,2-propylene glycol (PG), tetraethylene glycol (TEG) and polyethylene glycol (PEG 8000), that exhibit different physicochemical properties, have been utilized to regulate the size, structure, composition and the surface chemistry of NPs. The BMNPs were found to be of small crystalline size, $30-45 \mathrm{~nm}$, and high hydrophilicity, different wt\% percentage of organic coating and variable hydrodynamic size and surface charge. The antimicrobial activity of the BMNPs was evaluated against the bacterial strains B. subtilis, E. coli and fungus $S$. cerevisiae. The $\mathrm{IC}_{50}$ values for $\mathrm{CuFe}$ NPs were found significantly lower compared with $\mathrm{Cu}$ NPs of the same size, revealing an enhancement in the antimicrobial activity when iron and copper coexist in the crystal structure. The reactive oxygen species (ROS) production was measured intracellularly and extracellularly by the nitroblue tetrazolium assay in the fungal cultures. No extracellular ROS were measured suggesting that both $\mathrm{CuFe}$ and $\mathrm{Cu}$ NPs enter the fungal cells during the incubation, also verified by optical imaging of the fungal cells in the presence of NPs. Higher ROS concentrations were generated intracellularly for $\mathrm{CuFe}$ NPs supporting different red/ox reaction mechanisms.
\end{abstract}




\section{Introduction}

The abuse of antimicrobial drugs has led to an increasing number of infections associated with antibiotic-resistant microbes, forcing the global imperative for infectious disease research to develop novel materials with improved antimicrobial properties. Nanotechnology can provide compelling alternatives through the use of inorganic nanoparticles (NPs) with unique antimicrobial properties to kill pathogenic microorganisms ${ }^{2}$. Metallic NPs exhibit increased bioactivity while the proposed antimicrobial mechanisms are based on size effects, the ionic toxicity arising from the dissolution of the metal ions from surface of the NPs and the generation of extracellular and/or intracellular reactive oxygen species (ROS).

Bimetallic nanoparticles (BMNPs) are an emerging class of important materials that currently receive extensive attention owing to their unique physical and chemical properties which render them ideal candidates for various application ${ }^{7-12}$. Combining two metal elements can give rise to collective effects that significantly enhance specific properties, such as electric, magnetic and catalytic ${ }^{13,14}$. Meanwhile, antimicrobial activity is scarcely reported, although BMNPs can potentially achieve unique chemical transformations and synergetic effects can be presented. For instance, $\mathrm{Ag}$ and Au NPs display significant antimicrobial activity against a variety of microorganisms like bacteria and yeasts ${ }^{15,16}$ while enhanced antibacterial properties have been found for Au@Ag core-shell NPs that are attributed to the shell thickness and the more active silver atoms in the shell ${ }^{17}$. Additionally bimetallic Ag/Cu NPs exhibited superior performance compared to $\mathrm{Ag}$ and $\mathrm{Cu}$ NPs due to the synergistic action of the two different metals that coexist on the surface ${ }^{\mathbf{1 8}}$.

Generally, BMNPs constitute a thermodynamically stable blend of two distinct metals ${ }^{19}$, that can be classified to alloys and intermetallic compounds, in terms of atomic ordering. Based on the chemistry requirements of the different metal elements several synthetic protocols can be found spanning from simple co-reduction method, to more sophisticated ones such as thermal decomposition or seed-mediated growth and electrochemical processes. However, accessing these materials as nanocrystals is not always straightforward, and the development of appropriate synthetic pathways is ongoing. In specific, synthesis of CuFe NPs is considered challenging, as till now top down and solid state dry methods have mainly been reported that led to relative big sizes (100-2000nm), while high-temperature heating and/or annealing for a prolonged time was required in cases $^{\mathbf{2 0 - 2 2}}$. A wet chemical synthesis and an aerosol one have 
been referred where in both cases copper and/or iron oxides were formed as byproducts $^{\mathbf{2 3 2 4}}$. Recently, the biosynthesis of pure CuFe NPs via high temperature pyrolysis using a copper phthalocyanine based precursor and iron acetylacetonate was reported $^{25}$. Meanwhile the antimicrobial activity of CuFe NPs, according to our knowledge, is reported for the first time.

Our aim is the synthesis of bimetallic nanocrystals in the solution phase because it allows for exquisite control over their size, shape, composition, and structure. In the present study, we develop a wet chemical reproducible approach for the synthesis of pure CuFe NPs in an attempt to combine the high bio-reactivity of both metals. A modified polyol process under moderate temperature solvothermal conditions has been chosen. High boiling point polyalcohols serve as solvents, stabilizing agents and reducing agents, resulting in an effective control over the physicochemical characteristics of the NPs through size, shape, structure, surface chemistry known as 4S's. Given that, hydrophilicity and surface charge (positive, negative or neutral) are the most important factors that govern the affinity of the NPs to the cell surface, the cellular uptake and the toxicity of the NPs ${ }^{26}$. In so, 1,2propylene glycol (PG), tetraethylene glycol (TEG) and polyethylene glycol (PEG 8000) that exhibit different physical and chemical properties have been used in order to investigate the influence of the polyols on the composition and the surface chemistry of the as-produced BMNPs. Based on the molecular weight and structure of the utilized polyols, different capping ability is favored during synthesis while ionic and non-ionic surface coatings have been established, both rendering the BMNPs hydrophilic (soluble in water and polar solvents). The antimicrobial activity of $\mathrm{CuFe}$ NPs was investigated for the first time in comparison with $\mathrm{Cu}$ NPs, an already known antimicrobial candidate. For that purpose, monometallic Cu@PEG8000 NPs with similar size and percentage of organic coating are included in the studies ${ }^{5}$. The NPs were evaluated against the Gram-positive bacterial strain B. subtilis, the Gramnegative $E$. coli and the fungus $S$. cerevisiae in terms of growth inhibition by measuring the optical density of bacterial and fungal cultures. Apart from the estimation of Minimal Inhibitory Concentration (MIC) values ( IC $_{50}$ ), the ROS production was measured intracellularly and extracellularly by the nitroblue tetrazolium(NBT) reduction. The time-dependent stability of the fungal inhibitory activity of the NPs and the fungal cells' viability were also investigated. The fungal 
cell morphology in the absence and presence of NPs after $5 \mathrm{~h}$ of incubation has been observed by optical fluorescence microscopy.

\section{Experimental details}

\subsection{Materials}

All the reagents were of analytical grade and were used without any further purification. The products necessary for our experiments are the following: Copper (II) nitrate trihydrate $\mathrm{Cu}\left(\mathrm{NO}_{3}\right)_{2} \cdot 3 \mathrm{H}_{2} \mathrm{O}$ (Merck, $\geq 99.5 \%, \mathrm{M}=241.60 \mathrm{~g} / \mathrm{mol}$ ), Iron (III) nitrate nonahydrate $\mathrm{Fe}\left(\mathrm{NO}_{3}\right)_{3} \cdot 9 \mathrm{H}_{2} \mathrm{O}$ (Merck, $\geq 99.5 \%, \mathrm{M}=404 \mathrm{~g} / \mathrm{mol}$ ), polyethylene glycol (PEG) 8000 (Alfa aesar), tetraethylene glycol (TEG)(Aldrich, $\geq 99 \%$ ), 1,2propylene glycol (PG)(Riedel de Haen, $\geq 99.5 \%)$.

\subsection{Preparation of $\mathrm{Cu}_{\mathrm{x}} \mathrm{Fe}_{\mathrm{y}} \mathrm{NPs}$}

A modified polyol process under solvothermal conditions has been used for the preparation of the copper iron bimetallic NPs. For sample denoted as M1, $\mathrm{Fe}\left(\mathrm{NO}_{3}\right)_{3} \cdot 9 \mathrm{H}_{2} \mathrm{O}(0.5 \mathrm{mmol}, 0.202 \mathrm{~g})$ and $\mathrm{Cu}\left(\mathrm{NO}_{3}\right)_{2} \cdot 3 \mathrm{H}_{2} \mathrm{O}(0.5 \mathrm{mmol}, 0.121 \mathrm{~g})$ were mixed and dissolved in $8 \mathrm{~mL}$ of 1,2-propylene glycol, PG, while for M2 and M3 samples the same procedure has been followed with $8 \mathrm{~mL}$ of tetraethylene glycol, TEG, and $5.5 \mathrm{~g}$ of polyethylene glycol, PEG8000, respectively. The resulting solutions were stirred thoroughly and then transferred into a $23 \mathrm{~mL}$ Teflon-lined stainless-steel autoclave. The crystallization was carried out under autogenous pressure at $150{ }^{\circ} \mathrm{C}$ for $8 \mathrm{~h}$. Then the autoclave was cooled naturally to room temperature and after centrifugation at $5000 \mathrm{rpm}$, the supernatant liquids were discarded and a black-brown precipitate was obtained and washed with ethanol, at least three times, to remove the excess of ligands and the unreacted precursors.

\subsection{Characterization}

X-ray powder diffraction (XRD) measurements were performed on a Philips PW 1820 diffractometer at a scanning rate of $0.050 / 3 \mathrm{~s}$, in the $2 \theta$ range from 10 to $90^{\circ}$, 
with monochromatized $\mathrm{Cu} \mathrm{K} \alpha$ radiation $(\lambda=1.5406 \mathrm{~nm})$. Conventional Transmission Electron Microscopy (TEM) images were obtained with JEOL JEM 1010 microscope operating at $100 \mathrm{kV}$. For TEM observations we have used suspensions of the nanoparticles deposited onto carbon-coated copper grids. The elemental composition of the samples was estimated via Inductively Coupled Plasma Atomic Emission Spectroscopy (ICP-AES) analysis (iCAP 6300, Thermo Scientific). Fourier transform infrared spectra (FTIR) (350-4000 $\left.\mathrm{cm}^{-1}\right)$ were recorded using a Nicolet FT-IR 6700 spectrometer with samples prepared as $\mathrm{KBr}$ pellets. The micro-Raman measurements were performed at room temperature using the $515 \mathrm{~nm}$ line of a diode pumped solid state laser (Cobolt) as the excitation source. The power was kept at $0.1 \mathrm{~mW}$, and an $\mathrm{x} 100 \mu \mathrm{m}$ focus was used. The spectra were recorded using a micro-Raman LabRAM HR (HORIBA) system equipped with a peltier-cooled charge coupled device (CCD) detector. Thermogravimetric analysis (TGA) was performed using SETA-RAM SetSys- 1200 and carried out in the range from room temperature to $800^{\circ} \mathrm{C}$ at a heating rate of $10{ }^{\circ} \mathrm{Cmin}^{-1}$ under $\mathrm{N}_{2}$ atmosphere. Hydrodynamic diameters were determined by electrophoretic measurements, carried out at $25{ }^{\circ} \mathrm{C}$ by means of a VASCO Flex ${ }^{\mathrm{TM}}$ Particle Size Analyzer NanoQ V2.5.4.0 dynamic light scattering (DLS) while $\zeta$ potentials were determined by electrophoretic measurements, carried out at $25{ }^{\circ} \mathrm{C}$ by means of a NanoZetasizer, Nano ZS Malvern apparatus.

\subsection{Antimicrobial studies}

\subsubsection{Culture media.}

Two different cultivation media were used for the antimicrobial activity test: (i) the Luria- Bertani broth (LB) containing $1 \%(w / v)$ tryptone, $0.5 \%(w / v) ~ N a C l$ and $0.5 \%$ (w/v) yeast extract and (ii) the minimal medium salts broth (MMS) containing 1.5\% (w/v) glucose, $0.5 \%$ (w/v) $\mathrm{NH}_{4} \mathrm{Cl}, 0.5 \%(\mathrm{w} / \mathrm{v}) \mathrm{K}_{2} \mathrm{HPO}_{4}, 0.1 \%$ (w/v) $\mathrm{NaCl}, 0.01 \%$ $(\mathrm{w} / \mathrm{v}) \mathrm{MgSO}_{4} \cdot 7 \mathrm{H}_{2} \mathrm{O}$ and $0.1 \%(\mathrm{w} / \mathrm{v})$ yeast extract. The $\mathrm{pH}$ of the media was adjusted to 7.0 and subsequently, during the culture for the antimicrobial study it was monitored in removed aliquots and it was neutralized (if required).

\subsubsection{Antimicrobial screening of the NPs.}


Two bacterial species were used for the antibacterial studies: Gram-negative Escherichia coli (XL1) and Gram-positive Bacillus subtilis (ATCC 6633). The yeast S. cerevisiae, a unicellular eukaryotic model organism in molecular biology, was utilized for the antifungal study.

Bacterial cultures: The concentration of microorganisms in the cultivation medium was $10^{5}-10^{6} \mathrm{cfu} / \mathrm{mL}$. Bacterial growth was measured as an increase in absorbance at $600 \mathrm{~nm}$, determined using a spectrophotometer (Thermo Electron Corporation, Helios $\gamma$, USA). Thus, aliquots of $2 \mathrm{~mL}$ of MMS were inoculated with $20 \mu \mathrm{L}$ of a pre-culture of each bacterial strain, which was grown in LB overnight at its optimal growth temperature to assure the sufficient bacterial growth (cultures of reference). A second group of the same cultures, supplemented with nutrient media and the suitable concentrations of the NPs $(6,12.5,25,50$ and $100 \mu \mathrm{g} / \mathrm{mL}$ of NPs) was tested but devoid of inoculums and was used as a positive control. A third group of cultures, used as a negative control, was supplemented with nutrient media and inoculums, but devoid of NPs. The negative control indicated the microbial growth profile in the absence of NPs. The absorbance values for the positive control group were subtracted from the experimental values (cultures containing nutrient media, inoculum and NPs). All cultures were incubated at $37^{\circ} \mathrm{C}$.

Fungal culture: A series of different cultures were prepared, while each of them consists of $25 \mathrm{~mL}$ MMS inoculated with $5 \mathrm{mg}$ of yeast $S$. cerevisiae dry mass. Subsequently, the pre-cultures were grown at the optimal growth temperature $\left(30^{\circ} \mathrm{C}\right)$ until the exponential phase when they were separated in $2 \mathrm{~mL}$ aliquots. In a first group of aliquots, various concentrations of NPs were added to reach a final concentration of $6,12.5,25,50$ and $100 \mu \mathrm{g} / \mathrm{mL}$ of NPs, respectively. The stock solutions of the NPs $(2.5 \mathrm{mg} / \mathrm{mL})$ were prepared by formerly dissolving the NPs in distilled water. A second group of the same cultures, supplemented with the suitable concentrations of the NPs was tested but devoid of inoculums. These cultures were prepared to monitor any possible presence of fungus or microorganisms that are able to grow in this medium. A third group of cultures supplemented with inoculums but devoid of NPs was used and indicated the fungal growth profile in the absence of NPs (cultures of reference). All cultures were incubated at $30{ }^{\circ} \mathrm{C}$. Fungal growth was measured as an increase in absorbance at $600 \mathrm{~nm}$, determined using a spectrophotometer (Thermo Electron Corporation, Helios $\gamma$, USA). The absorbance values of the reference cultures were considered as the $100 \%$ of fungal growth in the 
calculation of percentage of yeast $S$. cerevisiae growth inhibition resulted from the presence of NPs.

The MIC in $\mu \mathrm{g} / \mathrm{mL}$ is defined as the lowest concentration of a compound or material that inhibits the $50 \%$ of the growth $\left(\mathrm{IC}_{50}\right.$ value) of an organism, which was determined based on growth inhibition of batch cultures, containing varying concentration of the NPs in suspension ${ }^{27}$. Three replicates were conducted for each dose $(6,12.5,25,50$ and $100 \mu \mathrm{g} / \mathrm{mL}$ of NPs) during the antimicrobial screening and a one-way ANOVA statistical analysis was employed by treating each dose as a different level (three replicates conducted for each level, 5 total levels). This provides the SD values for each dose as well as the $\mathrm{p}$ values of statistical comparison with the controls of the experiment. Additionally, a non linear curve fit-growth/sigmoidal-dose response was applied to estimate $\mathrm{IC}_{50}$ values along with $\mathrm{SD}$ error.

\subsubsection{Fungal cells' viability.}

The fungal cells' viability in the absence and the presence of various concentrations of NPs was also estimated by determining the degree of enzymatic hydrolysis of fluorescein diacetate (FDA, 3,6-diacetoxyfluoran) by $S$. cerevisiae cells. In detail, FDA is cleaved to fluorescein and acetic acid by different enzymes, such as proteases, lipases, and esterases ${ }^{\mathbf{2 8}}$. These enzymes are constituents of the primary metabolism of fungi and micro-organisms. The released fluorescein was measured by a fluorescence spectrophotometer.

A stock solution of FDA in acetone $(2 \mathrm{mg} / \mathrm{mL})$ was added in two series of $S$. cerevisiae cultures grown until the exponential phase in the absence and presence of various concentrations of NPs to reach a final FDA concentration of $10 \mu \mathrm{g} / \mathrm{mL}$. These cultures were incubated at $30{ }^{\circ} \mathrm{C}$ on a rotary shaker $(120 \mathrm{pm})$ for $1 \mathrm{~h}$ in total. After intervals of $15 \mathrm{~min}, 1 \mathrm{~mL}$ aliquots were removed from the cultures and placed in Eppendorf tubes. The hydrolysis of FDA was terminated by addition of acetone to reach a final acetone concentration of $50 \% \mathrm{v} / \mathrm{v}$. The mixture was centrifuged for $5 \mathrm{~min}$ in a multipurpose centrifuge (ScanSpeed 1236MG, LaboGene) at $10000 \mathrm{rpm}$ to remove suspended particles. The samples were excited at $\lambda_{\text {exc }}=495 \mathrm{~nm}$ and the fluorescence was measured at $\lambda_{\mathrm{em}}=525 \mathrm{~nm}$, with excitation and emission slits set at $2.5 \mathrm{~nm}$. In the percentage calculation of cell viability of yeast $S$. cerevisiae resulted 
from the presence of NPs, the emission values for the cultures of reference were considered as the $100 \%$ of fungus viability.

\subsubsection{Imaging of the fungal cells.}

Optical fluorescence microscopy images were obtained using an Optika B-500 TiFL with an HBO illumination system, triangular epi-fluorescence microscope equipped with a digital camera set (DIGI, 8megapixels) with an optical adapter and measuring software. The samples were excited at $\lambda_{\mathrm{exc}}=495 \mathrm{~nm}$ and the fluorescence was measured at $\lambda_{\mathrm{em}}=525 \mathrm{~nm}$.

\subsubsection{Reactive oxygen species assay}

The reactive oxygen species (ROS), which are produced extracellularly and/or intracellularly as a result of the treatment of $S$. cerevisiae cultures with Cu@PEG8000 and CuFe@PEG8000 NPs, were measured by the nitroblue tetrazolium (NBT) reduction protocol as previously described by $\mathrm{us}^{\mathbf{5}}$. For this purpose $200 \mu \mathrm{L}$ of fungal cells suspension (where $\mathrm{OD}_{600}=1.1$ ) in $\mathrm{MMS}$ was incubated with various concentrations of NPs $(12.5,25,50$ and $100 \mu \mathrm{g} / \mathrm{mL}$ of NPs, respectively) and $500 \mu \mathrm{L}$ of $1 \mathrm{mg} / \mathrm{mL} \mathrm{NBT}$ for $5 \mathrm{~h}$ at $30{ }^{\circ} \mathrm{C}$. Then, $100 \mu \mathrm{L}$ of $0.1 \mathrm{M} \mathrm{HCl}$ were added and the tubes were centrifuged at $1500 \mathrm{~g}$ for $10 \mathrm{~min}$. The supernatants were measured as OD at $575 \mathrm{~nm}$ to calculate the extracellular ROS. The pellets were treated with $600 \mu \mathrm{L}$ DMSO and were placed in a sonication bath to extract the reduced NBT. Finally, 500 $\mu \mathrm{L}$ MMS was added and Formazan blue obtained from cells was measured as OD at $575 \mathrm{~nm}$.

\subsection{Ionic release}

The release of copper and iron ions from the CuFe NPs (samples M1, M2, M3) into phosphate buffered saline (PBS) was studied by suspending $10 \mathrm{mg}$ of NPs in $100 \mathrm{~mL}$ PBS, followed by the sonication of the suspensions for $10 \mathrm{~min}$. The suspensions were 
kept in a rotary shaker under the same conditions as in the above studies and residual copper and iron ions concentration in the aqueous phase was determined after $24 \mathrm{~h}$ by flame atomic absorption spectrophotometry (FAAS) using a Perkin Elmer instrument, model AAnalyst 800.

\section{Results and discussion}

\section{Synthetic aspects and structural characterization}

The current trend in the production of monodispersed bimetallic nanoparticles is the use of wet chemical techniques which exploit red/ox reactions and decomposition phenomena resulting in a solution amongst its components (metal precursors, solvent, surfactants, and reducing agents). In our study, three different samples of $\mathrm{Cu}_{\mathrm{x}} \mathrm{Fe}_{\mathrm{y}} \mathrm{NPs}$ have been obtained when three types of polyols including PG, TEG and PEG-8000 (M1-M3 samples, respectively) directly reacted with $\mathrm{Fe}\left(\mathrm{NO}_{3}\right)_{3} \cdot 9 \mathrm{H}_{2} \mathrm{O}$ and $\mathrm{Cu}\left(\mathrm{NO}_{3}\right)_{2} \cdot 3 \mathrm{H}_{2} \mathrm{O}$ under solvothermal conditions inside an autoclave, in a hybrid polyol process. The reaction temperature, the reaction time and the initial ratio of the metal precursors were kept constant in all samples in order to investigate the impact of the reductive ability of each utilized polyol in the elemental composition of the BMNPs. The mechanism behind the reduction of metal precursors by the polyols remains poorly understood, however it is proposed by recent studies that polyols form intermediate complexes with the metals, prior to the production of metallic nanoparticles ${ }^{\mathbf{2 9 - 3 2}}$. Different metal precursors and/or polyols have an impact on the formation of the intermediate complexes, specifically on their stability, formation and decomposition temperatures. We used inorganic nitrate salts of iron and copper as precursors owing to their solubility in liquid polyols, resulting in ionic $\left(\mathrm{Fe}^{3+}, \mathrm{Cu}^{2+},\left[\mathrm{NO}_{3}\right]^{-}\right)$polyalcoholic solutions. In so, the formation of the polyol-metal complexes at a moderate temperature is facilitated ${ }^{33,34}$, unlike the case of using organometallic complexes as precursors (e.g. metal acetylacetones), where the intermediate complexes are formed either through ligand exchange or after the decomposition of the organometallic precursor, both happening at a higher temperature ${ }^{35,36}$. 
Powder XRD diffractograms for samples M1-M3, recorded at room temperature, are illustrated in Fig.1. The Bragg reflection peaks at $2 \theta=43.32^{\circ}$, $50.46^{\circ}$, and $74.14^{\circ}$ confirmed the formation of face centered cubic (fcc) $\mathrm{CuFe}$ bimetallic NPs (JCPDS no. 03-065-7002) and correspond to reflections from the 111, 200, and 220 planes, respectively ${ }^{\mathbf{2 5 , 4 2}}$. The appearance of sharp peaks indicated the good crystallinity of the produced NPs, while the high purity of the bimetallic NPs was verified through the absence of oxide, hydroxide and precursor reflections. For sample M3 synthesized in PEG 8000, the two distinct peaks appearing at $2 \theta=19.1^{\circ}$ and $22.9^{\circ}$ are attributed to the crystallization of PEG on the surface. In addition, all three samples contain partial graphitic carbon structures at $2 \theta \approx 24^{\circ}$ from the $(002)$ diffraction in their XRD pattern. The transformation of the polyols happens through dehydrogenation oxidation reactions where partial graphitic carbon is formed as a carbonaceous by-product ${ }^{34,43}$. During the synthesis of the NPs, polyols can decompose through heating ${ }^{\mathbf{3 9 , 4 0}}$, or participate in redox reductions with the ions $\left(\mathrm{Fe}^{3+}\right.$, $\mathrm{Cu}^{2+},\left[\mathrm{NO}_{3}\right]^{-}$) existing in the solution ${ }^{33}$. The products of these pathways are oxidized derivatives of polyols, like glycolaldehyde, glycoxylic acid, glycolic acid, oxalic acid, oxalates and $\mathrm{CO}_{2}$.

By taking the full width at half-maximum (FWHM) of the most intense peak (111) and based on the Scherrer equation the average crystallite sizes were calculated (Table.1). The variation of the size can be attributed to the different polyols used for each sample. Moreover, by using MDI's Jade software, the lattice parameter, $\alpha$, was calculated and found to be, 3.6182, 3.6177 and 3.6170 ̊ for sample M1, M2 and M3, respectively. The values are similar to that expected for metallic fcc $\mathrm{Cu}(\alpha=3.61 \AA)$ as the atomic radii of elemental copper $(1.28 \AA)$ and iron $(1.26 \AA)$ differ slightly (the difference is lower than 15\%) and thus, the dimensions and the structure of the fcc unit cell remain practically unaffected ${ }^{44}$, with a minor increase in the lattice parameter due to the iron atoms ${ }^{24}$. Additionally, the observed peaks are slightly shifted (to the left with increasing iron content) from the fcc metallic copper peaks (JCPDS no. 040836) as seen in Fig.2, which indicates that some copper atoms in the lattice have been substituted by iron ${ }^{25}$. The amorphous carbon formed as a by-product would significantly alter the dimensions of the fcc unit cell if carbon entered inside the cell and therefore, it is proposed it remains as a dead layer in the surface of the NPs.

The elemental composition of the samples was derived by ICP-AES analysis, where the "y" values (Table 1) revealed that each polyol provided bimetallic NPs with 
slightly dissimilar iron content with a calculated range of $0.54 \leq \mathrm{x} \leq 0.62 \& 0.38 \leq \mathrm{y} \leq$ 0.46. The diversity in composition is attributed solely to the reductive ability of each polyol as no additional reducing agents were used. The reductive ability of each polyol is related to the stability of the intermediate complexes that the polyol forms with the precursors. Polyols of high reductive ability are considered those one that form intermediates which are decomposed at lower temperatures and in short time while high molecular weight and long chain polyols exhibit weaker reductive ability as their intermediate complexes are more difficult to form and to decompose $\mathrm{s}^{\mathbf{3 8}}$. Previous reports of our research group revealed that, amongst PG, TEG and PEG 8000, PG showed the highest reductive ability while PEG 8000 showed the lowest ${ }^{37}$. The complete reduction of the iron species in the solution requires a strong reducing atmosphere, $\mathrm{Fe}^{3+}{ }_{(\mathrm{aq})}+3 \mathrm{e}^{-} \rightarrow \mathrm{Fe}_{(\mathrm{s})}=-0.04 \mathrm{~V}$, compared to the reduction of copper species that can easily happen even under mild reductive conditions, $\mathrm{Cu}^{2+}{ }_{(\mathrm{aq})}+2 \mathrm{e}^{-} \rightarrow$ $\mathrm{Cu}_{(\mathrm{s})}=0.34 \mathrm{~V}$. Thus, lower iron content $(\mathrm{y}=0.38)$ found in case of PEG-8000, when compared with the much smaller molecular weight TEG $(y=0.44)$. Apart from being the smallest of the polyols used, PG was utilized in a reaction temperature close to its boiling point $\left(188{ }^{\circ} \mathrm{C}\right)$, and therefore demonstrated the strongest reductive ability among the three polyols $(\mathrm{y}=0.46)$.

Generally, the mixing of two metals $\left(\mathrm{M}\right.$ and $\left.\mathrm{M}^{\prime}\right)$ is preferential when the $\mathrm{M}-$ $\mathrm{M}^{\prime}$ bond is stronger than both the $\mathrm{M}^{\prime}-\mathrm{M}^{\prime}$ and the $\mathrm{M}-\mathrm{M}$ bonds and the metals have analogous lattice parameters (crystal structure and lattice constant). These factors only describe some of the aspects of thermodynamically stable alloys, and there is always the possibility of attaining a nonequilibrium phase during the synthesis. At a relatively low reaction temperature, for example, the atoms are prevented from reaching their thermodynamically arranged phases. $\mathrm{Cu}$ has an fcc structure and a lattice parameter of $3.61 \AA$ while the regular crystal structure of $\mathrm{Fe}$ is a bcc one with a lattice parameter of $2.856 \AA$ A. However, iron can form a metastable fcc analogue, namely $\gamma$-Fe, with a lattice parameter of $3.642 \AA$. As found before for $\mathrm{Fe}_{100-\mathrm{x}} \mathrm{Cu}_{\mathrm{x}}$ alloys prepared by mechanical milling, when $x>40$ only fcc peaks appear in the XRD while for $x<20$ the bcc formation is favored ${ }^{\mathbf{4 1}}$. These results are accompanied with theoretical calculations and revealed that when $\mathrm{x}>40$, the free energy of the $\mathrm{FeCu}$ alloy is smaller for the fcc than the bcc structure ${ }^{\mathbf{4 1}}$. In our case, all synthesized $\mathrm{Cu}_{\mathrm{x}} \mathrm{Fe}_{\mathrm{y}} \mathrm{NPs}$ have a copper content of $x>50$ hence the formation of fcc BMNPs is observed. Moreover, due to the large gap in terms of reduction potential between the two metals, it is 
possible that copper as a more noble metal, gets reduced first while iron lags behind. Thus, it can be assumed that the as-formed Fe nuclei replace copper atoms in the already shaped fcc $\mathrm{Cu}$ matrix, indicated by the slight shift of the observed peaks from the fcc $\mathrm{Cu}$ pattern and the absence of bcc assigned peaks in the XRD of the samples (Fig.2).

The formation of the $\mathrm{CuFe}$ NPs can be given in three stages. First, $\mathrm{Cu}^{+2}$ and $\mathrm{Fe}^{3+}$ get reduced to $\mathrm{Cu}^{+1}$ and $\mathrm{Fe}^{2+}$, respectively, in the expense of polyol oxidation and according to their standard reduction potentials, $\mathrm{Cu}^{2+}{ }_{(\mathrm{aq})}+\mathrm{e}^{-} \rightarrow \mathrm{Cu}^{1+}{ }_{(\mathrm{aq})}=0.153 \mathrm{~V}$ and $\mathrm{Fe}^{3+}{ }_{(\mathrm{aq})}+\mathrm{e}^{-} \rightarrow \mathrm{Fe}^{2+}{ }_{\text {(aq) }}=0.77 \mathrm{~V}$. In the second stage, the reduction of the more noble metal on the less noble one is conducted: $\mathrm{Cu}^{1+}{ }_{(\mathrm{aq})}+\mathrm{Fe}^{2+}{ }_{(\mathrm{aq})} \rightarrow \mathrm{Cu}(\mathrm{s})+\mathrm{Fe}^{3+}{ }_{(\mathrm{aq})}$. In the third and final stage, the presence of graphitic carbon, a strong reducing agent, that was formed through dehydrogenation and oxidation reactions amongst polyols, favors the formation of metallic Fe NPs as given before in case of zero valent iron ${ }^{\mathbf{6 6}}$. The asformed $\mathrm{Fe}$ nuclei invade the $\mathrm{Cu}$ NPs unit cell by replacing copper atoms.

To further investigate the morphology of the samples, TEM bright-field images of the produced NPs were examined (Fig.3). The images of samples M1 and M2 portray nanoparticles with truncated and polygonal, almost spherical shapes and rather narrow size distributions, while in the image of M3 sample PEGylated arrays of NPs are observed, attributed to the crystallization of PEG 8000 (M3). The numberweighted distributions were built by counting over 150 NPs for samples M1 and M2 and were fitted with a standard log-normal function (Fig.S1 in SI). The mean particle sizes were $29.8 \pm 1.4$ and $37 \pm 0.7 \mathrm{~nm}$ for M1 and M2, respectively and are close to the values obtained from the XRD analysis. The formation of PEGylated arrays prevents us from effectively calculating the mean particle size for sample M3. Estimation for their size can be given through XRD and DLS measurements. The appearance of light and dark areas in the images indicates the coexistence of the two different metals (iron and copper) in a single-crystalline nanoparticle. However, the observation of structural defects on the NPs is a common characteristic of bimetallic NPs that verifies the alloy crystallinity ${ }^{\mathbf{4 5}}$. Moreover, these defects boost the reactivity of the produced NPs and render them ideal candidates for a variety of catalytic applications $\mathbf{4 6 , 4 7}$.

The colloidal stability of the CuFe NPs in water is an important issue for bio applications. Samples M1, M2, M3 were dispersed in water after the synthesis without any further modification and, by the means of DLS measurements, their 
hydrodynamic size was determined at 134, 249 and $146 \mathrm{~nm}$, respectively (mean size provided by Intensity \& Numbers measurements) (Fig.S2 in SI). These values provide the degree of aggregation of the BMNPs in water. Additionally, the $\zeta$-potential values of the aqueous suspensions of samples M1, M2 and M3 were found $-20,+0.4$ and $+0.6 \mathrm{mV}$, respectively. These values provide significant information on the stabilization mechanism for each sample and correlate well with previous studies of our group on PG, TEG and PEG 8000 as media ${ }^{37}$.

In case of M1, where 1,2-Propanodiol was used instead of 1,3-Propanodiol, the hydroxyl group in the second carbon of the organic chain remains unoxidized ${ }^{\mathbf{3 4}}$ and NPs with free hydroxyl groups extending from their surface are produced ${ }^{37}$. The negative charged coating for sample M1, as indicated by the zeta potential measurement, enables the electrostatic stabilization of the NPs in water and therefore shows the smallest hydrodynamic size amongst the three samples. For samples M2 and M3, steric exclusion forces lead to their stabilization in water as TEG and PEG form non-ionic coatings around the nanoparticles (no charge indication in their zetapotentials) and higher hydrodynamic values were observed. If steric stabilization of the particles is the main driving force, even a formulation of near zero zeta potential can be stable, because it is not the charge of the particles, but rather the excluded volume interaction that keeps particles from sticking to each other. The calculated hydrodynamic size for sample M3 (PEGylated NPs) was slightly higher than sample M1 but is still considered ideal for bio applications (less than $150 \mathrm{~nm}$ ) providing a steric barrier that prevents aggregation ${ }^{48}$. Sample M2 exhibited the highest hydrodynamic size due to aggregation phenomena as TEG has a much smaller chain than PEG8000 that binds on the surface of NPs through both ends of its chain.

The existence of the organic coating on the surface of the CuFe NPs has been confirmed by the FTIR spectra of the samples (Fig.4). The common nature of the polyols as surfactants is indicative in all cases. All peaks appear slightly shifted in comparison with the pure FTIR spectra of the polyols, indicating the binding of the surfactants on the surface of the NPs. A broad band around $3000-3500 \mathrm{~cm}^{-1}$ shows the $-\mathrm{OH}$ stretching mode of the glycol molecules and/or abdsorbed water. Sample M1 displays the sharpest peak in this region of the spectra compared with samples M2 and M3, owing to free hydroxyl groups on the surface of the NPs. Peaks at 2930 and $\sim 2850 \mathrm{~cm}^{-1}$ confirm the asymetric and symmetric strech of the $-\mathrm{CH}_{2}$ groups, while the broad band around 1610-1630 $\mathrm{cm}^{-1}$ can be attributed either to hydrogen bonding 
among neighboring surfactants and/or to glycolate derivatives ${ }^{49}$ confirming the presence of oxidized species of the polyols on the surface of the NPs. In the case of PG, these vibrations appear very strong indicating their high percentange of glycolates in the sample. PG exhibits the strongest reductive ability among the three polyols used, thus is prone to oxidation compared to TEG and PEG8000. At about 1420-1460 $\mathrm{cm}^{-1}$ bending modes of $\mathrm{C}-\mathrm{H}$ are detected as well as the $\mathrm{C}-\mathrm{O}$ stretch at $1100 \mathrm{~cm}^{-1}$. Additionally, bands at 1343, 1243 and $947 \mathrm{~cm}^{-1}$ correspond well to the $\mathrm{CH}_{2}-\mathrm{O}-\mathrm{CH}_{2}$ wagging (gauche), twisting and rocking modes, respectively. Finally, no clear peaks appear in the region of the spectra below $650 \mathrm{~cm}^{-1}$, confirming the metallic nature of the as synthesized NPs.

Raman spectroscopy was additionally used to verify further the composition of the NPs (Fig.5). Two broad bands appear at the spectra of the samples and, at first sight, the spectra are similar to that of the graphitic amorphous carbon ${ }^{\mathbf{5 0}}$. The band at $\sim 1580 \mathrm{~cm}^{-1}$ is characteristic for graphitic materials, namely the G-band, originating from the $\mathrm{E}_{2 \mathrm{~g}}$ mode (stretching vibrations in the honeycomb lattice of the graphitic layers). The appearance of the second band at $\sim 1350 \mathrm{~cm}^{-1}$, the defect-related D-band, is attributed to the finite particle-size effect and the highly distorted carbon structure. In a comparison of the Raman spectra of the NPs with that of perfect graphitic structure, the D band and G band are significantly broadened, indicating the presence of amorphous graphitic carbon ${ }^{\mathbf{5 0}}$. Again, no clear peaks associated with metal-oxygen bonds appear in the low frequency region of the spectra, verifying that no oxidation takes place during and after the synthesis and the produced NPs are metallic. It is important to mention that the Raman spectra were collected 2 months after the synthesis of the CuFe NPs, projecting the stability of the bimetallic NPs.

Thermogravimetric analysis (TGA) was conducted to calculate the amount of the organic coating on the surface of the produced NPs. Fig.6 shows the TGA curves of samples M1-M3. The cumulative organic contents were 31, 40, $61 \mathrm{wt} \%$, for M1, M2 and M3, respectively. For all samples, the decomposition of the surfactants begins around $200{ }^{\circ} \mathrm{C}$ and finishes right after $400{ }^{\circ} \mathrm{C}$. For sample M3 synthesized in PEG8000, a significant third weight loss was found up to $650{ }^{\circ} \mathrm{C}$. Regarding the decomposition at higher temperatures, a bi-layer formation of the organic coating is indicated as also confirmed elsewhere ${ }^{51}$. This is common phenomenon for high molecular weight surfactants like PEG8000 that curl around the surface of the nanoparticle. 
Leaching tests were performed by measuring the ionic release of PBS suspensions containing $100 \mu \mathrm{g} / \mathrm{mL}$ of NPs after $5 \mathrm{~h}$ and $24 \mathrm{~h}$ of incubation, using FAAS. The ionic release during $5 \mathrm{~h}$ of incubation was found beyond the resolution limit of the device $(<0.5 \mathrm{mg} / \mathrm{L})$, while during $24 \mathrm{~h}$ of incubation higher amounts of copper ions as compared to iron ions were recorded(Table 2), further supporting the placement of iron atoms inside the fcc unit cell.

\section{Antimicrobial screening.}

The antimicrobial activity of M1-M3 (average of three measurements) against the Gram-positive bacterial strain B. subtilis, the Gram-negative E. coli and the fungus $S$. cerevisiae was estimated in terms of growth inhibition by measuring the optical density of bacterial and fungal cultures at $600 \mathrm{~nm}, 5 \mathrm{~h}$ after the injection of various suspensions of NPs into the cultures. Two controls were also included: cultures grown without NPs and cultures grown in the presence of pure polyols.

The growth inhibition was determined after $5 \mathrm{~h}$ of incubation in the presence of various concentrations of the NPs $(6-100 \mu \mathrm{g} / \mathrm{mL})$ added at the logarithmic growth phase. The bacterial and fungal growth inhibition is observed in a concentrationdependent manner, as shown in Fig.7. The Minimal Inhibitory Concentration (MIC) values $\left(\mathrm{IC}_{50}\right)$ which inhibits the $50 \%$ of the bacterial and fungal growth were calculated for M1, M2, M3 and the results are summarized in Table 3. Microbial growth in the absence of NPs represents the 100\%. Also, MIC values of monometallic Cu@PEG8000 NPs previously reported by us ${ }^{5}$ are included for comparison in Table 3.

The recorded $\mathrm{IC}_{50}$ values suggest strong antibacterial activity against $E$. coli and B. subtilis, with stronger bacterial inhibition in the case of E. coli. The lowest $\mathrm{IC}_{50}$ values are observed for the PEGylated M3 NPs, $6.3 \pm 0.52$ and $7.8 \pm 0.893 \mu \mathrm{g} / \mathrm{mL}$, respectively. The reason lies in the structural and compositional differences of their cell membrane; Gram-positive bacteria have thicker peptidoglycan cell membranes compared to the Gram-negative ones and thus it is harder for the NPs to penetrate it, resulting in lower antibacterial response. However, B. subtilis has abundance of amines and carboxyl groups on its cell surface and thus greater affinity of copper ions towards these groups ${ }^{\mathbf{5 2}}$. Simultaneously, E. coli has a special cell membrane structure 
which possesses an important ability to resist antimicrobial agents ${ }^{\mathbf{5 3}}$. The fungal strain S. cerevisiae is much more resilient than these two bacterial strains and higher $\mathrm{IC}_{50}$ values are reported. The relative resistance of $S$. cerevisiae to the NPs compared to the bacteria could be attributed to the more rigid cell wall of the yeast cells ${ }^{\mathbf{5 4}}$. Additionally, the organic coating of the NPs seems to affect their antifungal ability and only the PEGylated NPs could significantly inhibit the fungal growth. The $\mathrm{IC}_{50}$ values calculated for the CuFe NPs are significantly lower than the values obtained for the monometallic $\mathrm{Cu}$ NPs revealing an enhancement in the antimicrobial activity in the case of the bimetallic NPs where iron and copper coexist in the crystal structure.

\section{Extracellular and intracellular ROS assay.}

To further investigate collective effects of copper and iron, the extracellular and intracellular ROS created during the incubation of $S$. cerevisiae cultures with $\mathrm{CuFe}$ and $\mathrm{Cu}$ NPs were measured. The production of extracellular and/or intracellular ROS is suggested as a possible antimicrobial mechanism of metallic nanoparticles ${ }^{\mathbf{2 , 3}}$. Transition-metal ions such as iron and copper donate or accept free electrons via red/ox reactions and help in the formation of free radicals through two main pathways. Both copper and iron can react with $\mathrm{O}_{2}$ producing $\mathrm{O}_{2} \bullet^{-}$according to the reactions:

$$
\begin{aligned}
& \mathrm{Fe}^{2+}+\mathrm{O}_{2} \rightarrow \mathrm{Fe}^{3+}+\mathrm{O}_{2}^{\bullet^{-}} \\
& \mathrm{Cu}^{1+}+\mathrm{O}_{2} \rightarrow \mathrm{Cu}^{2+}+\mathrm{O}_{2}^{\bullet^{-}}
\end{aligned}
$$

Moreover, ROS are formed through Fenton and Haber-Weiss chemistry where iron and copper can act as catalysts reacting with the $\mathrm{H}_{2} \mathrm{O}_{2}$ produced intracellularly by Superoxide dismutase (SOD):

$$
\begin{gathered}
2 \mathrm{H}^{+}+\mathrm{O}_{2} \bullet^{-}+\mathrm{O}_{2} \bullet^{-} \rightarrow \mathrm{H}_{2} \mathrm{O}_{2}+\mathrm{O}_{2}(\mathrm{SOD}) \\
\mathrm{Fe}^{2+}+\mathrm{H}_{2} \mathrm{O}_{2} \rightarrow \mathrm{Fe}^{3+}+\mathrm{OH} \bullet+\mathrm{OH}^{-} \text {(Fenton) } \\
\mathrm{Cu}^{+}+\mathrm{H}_{2} \mathrm{O}_{2} \rightarrow \mathrm{Cu}^{2+}+\mathrm{OH} \bullet+\mathrm{OH}^{-} \text {(Fenton) } \\
\mathrm{OH} \bullet+\mathrm{H}_{2} \mathrm{O}_{2} \rightarrow \mathrm{O}_{2} \bullet^{-}+\mathrm{H}^{+}+\mathrm{H}_{2} \mathrm{O} \\
\mathrm{O}_{2} \bullet^{-}+\mathrm{H}_{2} \mathrm{O}_{2}+\mathrm{Fe}^{3+} \rightarrow \mathrm{OH} \bullet+\mathrm{OH}^{-}+\mathrm{O}_{2}+\mathrm{Fe}^{2+} \text { (Haber-Weiss) }
\end{gathered}
$$




$$
\mathrm{O}_{2} \bullet^{-}+\mathrm{H}_{2} \mathrm{O}_{2}+\mathrm{Cu}^{2+} \rightarrow \mathrm{OH} \bullet+\mathrm{OH}^{-}+\mathrm{O}_{2}+\mathrm{Cu}^{1+}(\text { Haber-Weiss })
$$

The NBT assay was utilized to calculate the extracellular and intracellular superoxide radicals $\left(\mathrm{O}_{2} \bullet^{-}\right)$as previously described by $\mathrm{us}^{4}$. NBT is able to bypass the cell membrane and enter the fungal cells. In the presence of $\mathrm{O}_{2}{ }^{\bullet}$, NBT gets reduced to its formazan blue-derivative which can be quantified by measuring the absorbance of the solution at $575 \mathrm{~nm}$. In so, higher measured concentrations of the formazan bluederivative translate to higher production of $\mathrm{O}_{2}{ }^{-}$.

In the present work, no extracellular $\mathrm{O}_{2}{ }^{-}$were measured during the incubation of the fungal cultures with varying concentrations of NPs suggesting that both $\mathrm{CuFe}$ and $\mathrm{Cu}$ NPs enter the fungal cells during the incubation. Dose-dependent production of intracellular $\mathrm{O}_{2}{ }^{-}$is given in Fig.8. Treatment of fungal species with CuFe NPs (M3) generated higher concentrations of $\mathrm{O}_{2}{ }^{-}$compared to $\mathrm{Cu}$ NPs. The coexistence of copper and iron in the crystal structure appears to boost the production of intracellular $\mathrm{O}_{2} \bullet^{-}$as each metal display its own unique bioactivity and can lead to the production of ROS through different mechanisms. Additionally, copper and iron can participate in red/ox reactions with each other, leading to divalent iron and monovalent copper species that are able to catalyze the production of $\mathrm{O}_{2} \bullet^{-}$. An example can be given in the reaction:

$$
\mathrm{Cu}^{0}+\mathrm{Fe}^{3+} \rightarrow \mathrm{Fe}^{2+}+\mathrm{Cu}^{1+}
$$

Thus, the improved antimicrobial activity of the bimetallic CuFe NPs over monometallic $\mathrm{Cu}$ NPs is attributed to enhanced intracellular ROS production.

Time-dependent stability of the fungal inhibitory activity of the PEGylated NPs.

To ensure that the values obtained from the antimicrobial screening are indicators of a stable microbial inhibition, a time-dependent kinetic study of the antifungal activity of the PEGylated CuFe NPs was carried out. Fig.9 represents the growth curve of $S$. cerevisiae in the absence and presence of various concentrations of M3 NPs for a total of $28 \mathrm{~h}$. A series of fungal cultures were grown for $4 \mathrm{~h}$, followed by the addition of suspensions containing 6, 12.5, 25, 50 and $100 \mu \mathrm{g} / \mathrm{mL}$ of CuFe@PEG8000 (M3) NPs at the logarithmic growth phase. The optical density 
values for all cultures (control and NPs containing cultures) were measured 5, 10 and $24 \mathrm{~h}$ after the injection of the NPs. After $10 \mathrm{~h}$ of incubation with the NPs, the yeast partially overcomes the stress induced by the NPs and manages to slightly lessen the growth inhibition caused by them. This phenomenon becomes more intense after $24 \mathrm{~h}$ of incubation but is mainly observed in the cultures grown in the presence of low concentrations of NPs, whereas cultures supplemented with high concentrations of NPs maintain a more stable inhibitory profile.

This time-dependent decrease in the growth inhibition of the fungus could be linked to the iron homeostasis in fungi. Iron is an important cofactor required for a number of essential cellular functions and yeast strains utilize a variety of mechanisms to assimilate the elemental iron either from the nanoparticles and/or the ferric ions released from the NPs. Iron is not bio-available in all of its forms and its uptake, depending on the microbial strain investigated, could be achieved either by lowering the external $\mathrm{pH}$ to render ferric iron more soluble or by reducing ferric iron to the relatively soluble ferrous form and employing ferric ion chelators as solubilizing agents ${ }^{\mathbf{5 5}}$. Moreover, copper and iron homeostasis are ultimately linked ${ }^{\mathbf{5 6}}$ and excess $\mathrm{Cu}$ could lead to an increase in iron acquisition and sulfur assimilation in fungi due to a decreased iron-sulfur cluster stability both during their biogenesis and when bound to their target proteins ${ }^{57,58}$. S. cerevisiae growth is largely depended on an elemental iron uptake system. First, ferric iron, Fe (III), is reduced to ferrous iron, $\mathrm{Fe}$ (II), by an extracellular iron reductase. Fe (II) is bound by the copper-dependent oxidase Fet $3 p$ and the re-oxidized Fe (III) is finally transferred to the Ftr1p receptor for uptake ${ }^{59}$. After 10 and $24 \mathrm{~h}$ of incubation with the NPs, the yeast manages to partially fulfill its need for iron either by taking directly the ions released from the NPs or by assimilating the NPs. The normal iron homeostasis in fungi requires the presence of copper, which is also an essential nutrient. High-affinity iron uptake in the yeast $S$. cerevisiae is $\mathrm{Cu}^{2+}$-dependent because Fet3p, a component of the high-affinity iron transporter complex, is a $\mathrm{Cu}^{2+}$-dependent ferrous oxidase ${ }^{\mathbf{6 0}}$. The above tendency appears after $10 \mathrm{~h}$ of incubation, as no ionic release takes place prior to that time, according to the leaching tests.

The $\mathrm{IC}_{50}$ values for fungal inhibition were calculated for all three time periods (5, 10 and $24 \mathrm{~h}$ of incubation) and can been seen in Fig.10 along with the nonlinear fitting of the experimental measurements. Fungal growth in the absence of NPs represents the $100 \%$ in each time period. The $\mathrm{IC}_{50}$ values for 5,10 and $24 \mathrm{~h}$ of 
incubation are $34.34 \pm 2.32,38.4 \pm 2.27,50.3 \pm 1.72 \mu \mathrm{g} / \mathrm{mL}$, respectively. The timedependant decrease in the growth inhibition of the fungus is reflected in the $\mathrm{IC}_{50}$ values. Still, the $50.3 \pm 1.72 \mu \mathrm{g} / \mathrm{mL} \mathrm{IC}_{50}$ value calculated after $24 \mathrm{~h}$ of incubation with the bimetallic CuFe@PEG8000 NPs is lower than the $63 \pm 1.72 \mu \mathrm{g} / \mathrm{mL} \mathrm{IC}_{50}$ value reported for the monometallic Cu@PEG8000 NPs.

Evaluation of the Fungal Cells' viability.

The antifungal activity of the PEGylated M3 NPs toward yeast S. cerevisiae was also estimated in terms of cell viability by a fluorescence method, which can effectively distinguish between viable and lysed cells. In detail, the fungus viability was estimated by determining the degree of esterase activity of $S$. cerevisiae cells. Fluorescein diacetate (FDA) was utilized as a substrate since it is enzymatically cleaved into fluorescein and acetic acid only when the fungal cells are metabolically active. The non fluorescent FDA is able to bypass the cell membrane and enter the fungal cells, where it is cleaved, resulting in the release of the fluorescent fluorescein.

Fungal cultures, incubated with various concentrations of M3 NPs for $5 \mathrm{~h}$, were exposed to FDA solutions and the released fluorescein was estimated for each culture via fluorescence measurements. Results are shown in Fig.11, where the fluorescence measured for the culture of reference (control) was considered as an indicator of $100 \%$ cell viability. A decrease in the percentage of cell viability is observed in a concentration-dependent manner and the results are summarized in Table 4. The total esterase activity is affected in the presence of the NPs, resulting in a cell viability of $25 \%$ and lower in the case of fungal cultures incubated with high concentrations (50 and $100 \mu \mathrm{g} / \mathrm{ml})$. In so, the fungal growth inhibition that was verified through the optical density measurements can be attributed to a decrease in the number of viable fungal cells, resulting from the incubation of the fungal cultures with the bimetallic NPs. 
Optical imaging of the Fungal Cells.

The release of the green fluorescent fluorescein compound through the enzymatic cleavage of FDA by the viable fungal cells enables their illustration via fluorescence microcopy. In that manner, the fungal cell morphology in the absence and presence of M1, M2 and M3 NPs after $5 \mathrm{~h}$ of incubation can be observed in the received optical images of Fig.12. The untreated cells display a round shape with an integrate cell wall/membrane. The morphology of the cells treated with M1 and M2 NPs did not change, hence no significant fungal inhibition was observed in the optical density measurements. However, in cells treated with the PEGylated M3 NPs drastic alternations in the shape and cell wall/membrane integrity can be viewed. These alternations stem from the ability of PEGylated M3 NPs to penetrate the cells and remain flexibly active inside the cells, in the form of PEGylated arrays. Similarly, the PEGylated antibacterial peptide Bac7 (1-35) protects mice against Salmonella typhimurium infection by penetrating into cells and it exploits the same transporter with the non-PEGylated peptide ${ }^{61}$. Bacterial growth kinetics of S. typhimurium in the presence of this PEGylated peptide showed a rapid antibacterial effect, which initiated immediately without delay, suggesting that the PEGylated form was responsible for the antibacterial activity ${ }^{\mathbf{6 1}}$. Additionally PEG is reported to promote biocompatibility and biodegradability in hydroxyapatite/PEG/Ag nanocomposite particles ${ }^{\mathbf{6 2}}$. It is wellestablished that the surface charge, hydrodynamic size and colloidal stability of the NPs can play a significant role in cellular uptake ${ }^{\mathbf{6 3 , 6 4}}$. The M1 NPs failed to massively penetrate the cells due to the electrostatic repulsions between the negatively charged NPs and membranes. The M2 and M3 NPs, with neutral surface charge, penetrated the cells but only the M3 NPs could destroy the membrane structure. In the cells treated with CuFe@TEG M2 NPs, the intense aggregation of the NPs is obvious inside the cells, as it is supported by the colloidal stability studies, and the NPs remain inactive inside the cells, viewed by an antifungal perspective.

\section{Conclusions}

Bimetallic nanoparticles are an emerging class of materials exhibiting remarkable properties that can be optimized in terms of composition, in addition to their size, 
shape and structure. However, there is still much research to be done for attaining precisely controlled and reproducible syntheses. In the present study the use of a wetchemical modified polyol process under moderate temperature solvothermal conditions proved fruitful for the synthesis of $\mathrm{CuFe}$ bimetallic NPs without any copper and iron oxide phases. The utilization of a closed system of adiabatic conditions (autoclave) grants stability to the synthesized nanoparticles and provides reproducible results. The formation mechanism is based on red/ox reactions and decomposition phenomena that occur amongst copper, iron and polyols. Moreover, the use of biocompatible polyols, in a triple role of solvent, reducing agent and surfactant eliminates the appearance of by-products and leads to the isolation of coated nanoparticles. The hybrid organic/inorganic nanomaterials are readily dispersed in water and no post-synthetic transformations are required. As the composition and the organic coating of the nanoparticles can regulate their biological behavior and given the fact that copper and iron follow different mechanisms in the production of intracellular ROS, PEGylated CuFe NPs are found to exhibit enhanced antimicrobial activity compared to PEGylated $\mathrm{Cu}$ NPs. Higher ROS concentrations were generated intracellularly for CuFe NPs supporting different red/ox reaction mechanisms. Taking into account the pleiotropic effects of the metals ${ }^{65}$ on microorganism's metabolism, the present results enable for extension of the studies to significantly dissimilar elemental compositions of $\mathrm{Cu}_{\mathrm{x}} \mathrm{Fe}_{\mathrm{y}} \mathrm{NPs}$ (where $0 \leq \mathrm{x} \leq 100$ and $0 \leq \mathrm{y} \leq 100)$ in order to explore how copper/iron excess affects metabolism and cell viability differently (mitochondrial damage, DNA damage, enzymatic activity, etc.). 


\section{References}

1) J.T. Seil, T.J. Webster, Antimicrobial Applications of Nanotechnology: Methods and Literature. Int. J. Nanomed. 7 (2012) 2767-2781.

2) M.J. Hajipour, K.M. Fromm, A.A. Ashkarran, D. Jimenez de Aberasturi, I. R. de Larramendi, T. Rojo, V. Serpooshan, W.J. Parak, M. Mahmoudi, Antibacterial Properties of Nanoparticles. Trends Biotechnol. 30 (2012) 499-511.

3) S.J. Soenen, W.J. Parak, J. Rejman, B. Manshian, (Intra)Cellular Stability of Inorganic Nanoparticles: Effects on Cytotoxicity, Particle Functionality, and Biomedical Applications. Chem. Rev. 115 (2015) 2109-2135.

4) K. Giannousi, G. Sarafidis, S. Mourdikoudis, A. Pantazaki, C. Dendrinou-Samara, Selective Synthesis of $\mathrm{Cu}_{2} \mathrm{O}$ and $\mathrm{Cu} / \mathrm{Cu}_{2} \mathrm{O}$ NPs: Antifungal Activity to Yeast Saccharomyces cerevisiae and DNA Interaction. Inorg. Chem. 53 (2014) 9657-9666.

5) K. Giannousi, K. Lafazanis, J. Arvanitidis, A. Pantazaki, C. Dendrinou-Samara, Hydrothermal Synthesis of Copper Based Nanoparticles: Antimicrobial Screening and Interaction with DNA. J. Inorg. Biochem. 133 (2014) 24-32.

6) M. Auffan, J. Rose, M.R. Wiesner, J.Y. Bottero, Chemical Stability of Metallic Nanoparticles: a Parameter Controlling their Potential Cellular Toxicity in vitro. Environ. Pollut. 157 (2009) 1127-1133.

7) B. Lim, M. Jiang, P.H. Camargo, E.C. Cho, J. Tao, X. Lu, Y. Zhu, Y. Xia, Pd-Pt Bimetallic Nanodendrites with High Activity for Oxygen Reduction. Science 324 (2009) 1302-1305.

8) Y. Bing, H. Liu, L. Zhang, D. Ghosh, J. Zhang, Nanostructured Pt-alloy Electrocatalysts for PEM Fuel Cell Oxygen Reduction Reaction. Chem. Soc. Rev. 39 (2010) 2184-2202. 
9) H.M. Song, W.S. Kim, Y.B. Lee, J.H. Hong, H.G. Lee, N.H. Hur, Chemically Ordered $\mathrm{FePt}_{3}$ Nanoparticles Synthesized by a Bimetallic Precursor and their Magnetic Transitions. J. Mater. Chem. 19 (2009) 3677-3681.

10) C.Y. Fu, K.W. Kho, U.S. Dinish, Z.Y. Koh, O. Malini, Enhancement in SERS Intensity with Hierarchical Nanostructures by Bimetallic Deposition Approach. $J$. Raman Spectrosc. 43 (2012) 977-985.

11) S. Guo, E. Wang, Functional Micro/Nanostructures: Simple Synthesis and Application in Sensors, Fuel Cells, and Gene Delivery. Acc. Chem. Res. 44 (2011) 491-500.

12) S. Lee, S. Kim, J. Choo, S.Y. Shin, Y.H. Lee, H.Y. Choi, S. Ha, K. Kang, C.H. Oh, Biological Imaging of HEK293 Cells Expressing PLCgamma1 Using Surfaceenhanced Raman Microscopy. Anal. Chem. 79 (2007) 916-922.

13) S.E. Habas, H. Lee, V. Radmilovic, G.A. Somorjai, P. Yang, Shaping Binary Metal Nanocrystals through Epitaxial Seeded Growth. Nat. Mater. 6 (2007) 692-697. 14) K.D. Gilroy, A. Ruditskiy, H.C. Peng, D. Qin, Y. Xia, Bimetallic Nanocrystals: Syntheses, Properties, and Applications. Chem. Rev. 116 (2016) 10414-10472.

15) L.C. Giannossa, D. Longano, N. Ditaranto, M.A. Nitti, F. Paladini, M. Pollini, M. Rai, A. Sannino, A. Valentini, Metal Nanoantimicrobials for Textile Applications. Nanotechnol. Rev. 2 (2013) 307-331.

16) S.M. Dizaj, F. Lotfipour, M. Barzegar-Jalali, M.H. Zarrintan, K. Adibkia, Antimicrobial Activity of the Metals and Metal Oxide Nanoparticles. Mater. Sci. Eng. C, 44 (2014) 278-284.

17) M. Banerjee, S. Sharma, A. Chattopadhyay, S.S. Ghosh, Enhanced Antibacterial Activity of Bimetallic Gold-Silver Core-shell Nanoparticles at Low Silver Concentration. Nanoscale 3 (2011) 5120-5125. 
18) A. Perdikaki, A. Galeou, G. Pilatos, I. Karatasios, N.K. Kanellopoulos, A. Prombona, G.N. Karanikolos, $\mathrm{Ag}$ and $\mathrm{Cu}$ Monometallic and $\mathrm{Ag} / \mathrm{Cu}$ Bimetallic Nanoparticle-Graphene Composites with Enhanced Antibacterial Performance. ACS Appl. Mater. Interfaces 8 (2016) 27498-27510.

19) D. Wang, Q. Peng, Y. Li, Nanocrystalline Intermetallics and Alloys. Nano Res. 3, (2010) 574-580.

20) M. Azabou, H. lbn Gharsallah, L. Escoda, J.J. Sunol, A.W. Kolsi, M. Khitouni, Mechanochemical Reactions in Nanocrystalline $\mathrm{Cu}-\mathrm{Fe}$ System Induced by Mechanical Alloying in Air Atmosphere. Powder Technol. 224 (2012) 338-344.

21) J.Z. Jiang, J.S. Olsen, L. Gerward, S. Morup, Compressibility of Nanostructured Fe-Cu Materials Prepared by Mechanical Milling. Nanostruct. Mater. 12 (1999) 847850.

22) G. Shi, X. Chen, H. Jiang, Z. Wand, H. Tang, Y. Fan, Strengthening Mechanisms of Fe Nanoparticles for Single Crystal Cu-Fe Alloy. Mater. Sci. Eng. A. 636 (2015) 43-47.

23) K. Xiao, Z. Bao, X. Qi, X. Wang, L. Zhong, K. Fang, M. Lin, Y. Sun, Structural Evolution of CuFe Bimetallic Nanoparticles for Higher Alcohol Synthesis. J. Mol. Catal. A: Chem. 378 (2013) 319-325.

24) E.A. Shafranovsky, Y.L. Petrov, L. Casas, E. Molins, Structural and Mossbauer Studies of Aerosol FeCu Nanoparticles in a Wide Composition Range. J. Nanopart. Res. 13 (2011) 4913-4928.

25) G. Nam, J. Park, M. Choi, P. Oh, S. Park, M.G. Kim, N. Park, J. Cho, J.S. Lee, Carbon-Coated Core-Shell $\mathrm{Fe}-\mathrm{Cu}$ Nanoparticles as Highly Active and Durable Electrocatalysts for a Zn-Air Battery. ACS Nano. 9 (2015) 6493-6501. 
26) A.K. Suresh, D.A. Pelletier, M.J. Doktycz, Relating nanomaterial properties and microbial toxicity. Nanoscale. 5 (2013) 463.

27) D.N. Williams, S.H. Ehrman, T.R. Pulliam-Holoman, Evaluation of the Microbial Growth Response to Inorganic Nanoparticles. J. Nanobiotechnol. 4:3 (2006).

28) P. Verma, J. Dyckmans, H. Militz, C. Mai, Determination of Fungal Activity in Modified Wood by Means of Micro-calorimetry and Determination of Total Esterase Activity. Appl. Microbiol. Biotechnol. 80 (2008) 125-133.

29) K.J. Carroll, J. Ulises-Reveles, M.D. Shultz, S.N. Khanna, E.E. Carpenter, Preparation of Elemental $\mathrm{Cu}$ and $\mathrm{Ni}$ Nanoparticles by the Polyol Method: An Experimental and Theoretical Approach. J. Phys. Chem. C. 115 (2011) 2656-2664.

30) X. Jiang, Y. Wang, T. Herricks, Y. Xia, Ethylene Glycol-mediated Synthesis of Metal Oxide Nanowires. J. Mater. Chem. 14 (2004) 695-703.

31) R.W.J. Scott, N. Coombs, G.A. Ozin, Non-aqueous Synthesis of Mesostructured Tin Dioxide. J. Mater. Chem. 13 (2003) 969-974.

32) Y. Wang, X. Jiang, Y. Xia, A Solution-phase, Precursor Route to Polycrystalline $\mathrm{SnO}_{2}$ Nanowires that can be used for Gas Sensing under Ambient Conditions. J. Am. Chem. Soc. 125 (2003) 16176-16177.

33) C. Caizer, M. Ştefănescu, Synthesis and Characterization of Copper Substituted Nickel Nano-Ferrites by Citrate-Gel Technique. J. Phys. D: Appl. Phys. 35 (2002) 3035-3040.

34) M. Ştefănescu, M. Stoia, O. Ştefănescu, P. Barvinshci, The Interaction Between TEOS and Some Polyols. J. Therm. Anal. Calorim. 88 (2007) 459-464.

35) B. Jeyadavan, K. Urakawa, A. Hobo, N. Chinnasamy, K. Shinoda, K. Tohji, D.D.J. Djayaprawira, M. Tsunoda, M. Takahashi, Direct Synthesis of fct-FePt Nanoparticles by Chemical Route. Jpn. J. Appl. Phys. 42 (2003) 350-352. 
36) S. Kang, S. Shi, G. X. Miao, Z. Jia, D. E. Nikles, J.W. Harrell, Synthesis and Magnetic Properties of FePt Nanoparticles with Hard Nonmagnetic Shells. J. Nanosci. Nanotechnol. 7 (2007) 350-355.

37) K. Vamvakidis, M. Katsikini, G. Vourlias, M. Angelakeris, E.C. Paloura, C. Dendrinou-Samara, Composition and hydrophilicity control of Mn-doped ferrite $\left(\mathrm{Mn}_{\mathrm{x}} \mathrm{Fe}_{3-\mathrm{x}} \mathrm{O}_{4}\right)$ nanoparticles induced by polyol differentiation. Dalton Trans. 44 (2015) 5396-5406.

38) A.J. Biacchi, R.E. Schaak, The Solvent Matters: Kinetic versus Thermodynamic Shape Control in the Polyol Synthesis of Rhodium Nanoparticles. ACS Nano 5 (2011) 8089-8099.

39) C.B. Webb, In The veterinary ICU book, 1st ed; W. E. Wingfiled, M. R. Raffe, Teton New Media, USA, 2002; Chapter 76, pp 1042-1048.

40) V. A. Yaylayan, S. Harty-Majors, A.A. Ismail, Investigation of the Mechanism of Dissociation of Glycolaldehyde dimer (2,5-dihydroxy-1,4-dioxane) by FTIR Spectroscopy. Carbohydr. Res. 309 (1998) 31-38.

41) P.J. Schilling, J.H. He, J. Cheng, E. Ma, Extended x-ray absorption fine structure of metastable bcc and fcc phases in mechanically alloyed Fe-Cu. Appl. Phys. Lett. 68 (1996) 767-769.

42) Transactions of the Metallurgical Society of AIME; American Institute of Mining, Metallurgical and Petroleum Engineers: New York, 1958.

43) H. Dong, M. Roming, C. Feldmann, Unexpected Fluorescence of Polyols and PEGylated Nanoparticles Derived from Carbon Dot Formation. Part. Part. Syst. Charact. 32 (2015) 467-475.

44) R.A. Butera, D.H. Waldeck, X-ray Diffraction Investigation of Alloys. J. Chem. Educ. 74 (1997) 115-119. 
45) W.J. Huang, R. Sun, J. Tao, L.D. Menard, R.G. Nuzzo, J.M. Zuo, Coordinationdependent Surface Atomic Contraction in Nanocrystals Revealed by Coherent Diffraction. Nat. Mater. 7 (2008) 308-313.

46) G.A. Somorjai, K.M. Bratlie, M.O. Montano, J.Y. Park, Dynamics of Surface Catalyzed Reactions; the Roles of Surface Defects, Surface Diffusion, and Hot Electrons. J. Phys. Chem. B 110 (2006) 20014-20022.

47) C.D. Lorenz, R. Haghgooie, C. Kennebrew, R.M. Ziff, The Effects of Surface Defects in a Catalysis Model. Surf. Sci. 517 (2002) 75-86.

48) Y. Park, R.D. Whitaker, R.J. Nap, J.L. Paulsen, V. Mathiyazhagan, L. H. Doerrer, Y.Q. Song, M.D. Hürlimann, I. Szleifer, J.Y. Wong, Stability of Superparamagnetic Iron Oxide Nanoparticles at Different $\mathrm{pH}$ Values: Experimental and Theoretical Analysis. Langmuir . 28 (2012) 6246-6255.

49) R. Sulaxna Prasad, A. Kumar, Kinetics of Thermal Decomposition of Iron (III) Dicarboxylate Complexes. J. Therm. Anal. Calorim. 81 (2005) 441-450.

50) A.C. Ferrari, J. Robertson, Raman Spectroscopy of Amorphous, Nanostructured, Diamond-like Carbon, and Nanodiamond. Philos. Trans. R. Soc. A. 362 (2004) 24772512.

51) L. Shen, P.E. Laibinis, T.A. Hatton, Bilayer Surfactant Stabilized Magnetic Fluids: Synthesis and Interactions at Interfaces. Langmuir. 15 (1999) 447-453.

52) T.J. Beveridge, R.G. Murray, Sites of Metal Deposition in the Cell Wall of Bacillus subtilis. J. Bacteriol. 141 (1980) 876-887.

53) X. Liang, M. Sun, L. Li, R. Qiao, K. Chen, Q. Xiao, F. Xu, Preparation and Antibacterial Activities of Polyaniline/ $\mathrm{Cu}_{0.05} \mathrm{Zn}_{0.95} \mathrm{O}$ Nanocomposites. Dalton Trans. 41 (2012) 2804-2811. 
54) K. Kasemets, A. Ivask, H.C. Dubourguier, A. Kahru, Toxicity of Nanoparticles of $\mathrm{ZnO}, \mathrm{CuO}$ and $\mathrm{TiO} 2$ to Yeast Saccharomyces cerevisiae. Toxicol. In Vitro. 23 (2012) 1116-1122.

55) M.L. Guerinot, Microbial Iron Transport. Annu. Rev. Microbiol. 48 (1994) $743-$ 772.

56) X. Shi, K. Chabarek, A. Budai, Z. Zhu, Iron Requirement for GAL Gene Induction in the Yeast Saccharomyces cerevisiae. J. Biol. Chem. 278 (2003) 4311043113.

57) L. Macomber, J.A. Imlay, The Iron-sulfur Clusters of Dehydratases are Primary Intracellular Targets of Copper Toxicity. Proc. Natl. Acad. Sci. U. S. A. 106 (2009) 8344-8349.

58) S. Chillappagari, A. Seubert, H. Trip, O.P. Kuipers, M.A. Marahiel, M. Miethke, Copper Stress Affects Iron Homeostasis by Destabilizing Iron-sulfur Cluster Formation in Bacillus Subtilis. J. Bacteriol. 192 (2010) 2512-2524.

59) J. Ollinger, K.B. Song, H. Antelmann, M. Hecker, J.D Helmann,. Role of the Fur Regulon in Iron Transport in Bacillus Subtilis. J. Bacteriol. 188 (2006) 3664-3673.

60) D.J. Kosman, Molecular Mechanisms of Iron Uptake in Fungi. Mol. Microbiol. 47 (2003) 1185-1197.

61) M. Benincasa, S. Zahariev, C. Pelillo, A. Milan, R. Gennaro, M. Scocchi, PEGylation of the Peptide Bac7(1-35) Reduces Renal Clearance while Retaining Antibacterial Activity and Bacterial Cell Penetration Capacity. Eur. J. Med. Chem. 95 (2015) 210-219.

62) S. Jegatheeswaran, M. Sundrarajan, PEGylation of Novel Hydroxyapatite/Peg/Ag Nanocomposite Particles to Improve Its Antibacterial Efficacy. Mater. Sci. Eng. C. 51 (2015) 174-181. 
63) A. Asati, S. Santra, C. Kaittanis, J.M. Perez, Surface-charge-dependent Cell Localization and Cytotoxicity of Cerium Oxide Nanoparticles. ACS Nano. 4 (2010) $5321-5331$.

64) M. Liang, I.C. Lin, M.R. Whittaker, R.F. Minchin, M.J. Monteiro, I. Toth, Cellular Uptake of Densely Packed Polymer Coatings on Gold Nanoparticles. ACS Nano. 4 (2010) 403-413.

65) J. Stevenson, A. Barwinska-Sendra, E. Tarrant, K. J. Waldron. Mechanism of action and applications of the antimicrobial properties of copper. Microbial pathogens and strategies for combating them: science, technology and education. 2 (2013) 468479.

66) M. Stefaniuk, P. Oleszczuk, Y.S. Ok, Review on nano zerovalent iron (nZVI): From synthesis to environmental applications, Chem. Eng. J. 287 (2016) 618-632. 
5. Tables and Figures.

Table 1. Chemical and structural characteristics of the samples.

\begin{tabular}{|c|c|c|c|c|c|}
\hline Sample & Polyol & $\begin{array}{l}\text { Formula } \\
\text { by ICP, } \\
\mathrm{Cu}_{\mathbf{x}} \mathrm{Fe}_{\mathrm{y}}\end{array}$ & dXRD (nm) & $\begin{array}{l}\text { dTEM } \\
(\mathbf{n m})\end{array}$ & $\begin{array}{l}\text { dDLS } \\
(\mathbf{n m})\end{array}$ \\
\hline M1 & PG & $\mathrm{Cu}_{0,54} \mathrm{Fe}_{0,46}$ & 34 & $29.8 \pm 1.4$ & 134 \\
\hline M2 & TEG & $\mathrm{Cu}_{0,56} \mathrm{Fe}_{0,44}$ & 43 & $37 \pm 0.7$ & 249 \\
\hline M3 & PEG8000 & $\mathrm{Cu}_{0,62} \mathrm{Fe}_{0,38}$ & 40 & $\begin{array}{l}\text { PEGylated } \\
\text { arrays }\end{array}$ & 146 \\
\hline
\end{tabular}

Table 2. Ionic release measurements for samples M1, M2 and M3 in PBS during $24 \mathrm{~h}$ of incubation.

\begin{tabular}{lll}
\hline Sample & $\begin{array}{l}\text { Cu } \\
\text { release per } \\
\mathbf{1 0 0} \boldsymbol{\mu g} / \mathbf{m L}\end{array}$ & $\begin{array}{l}\text { release per } \\
\mathbf{1 0 0} \boldsymbol{\mu g} / \mathbf{m L}\end{array}$ \\
\hline M1 & 23.325 & 0.715 \\
M2 & 22.455 & 0.63 \\
M3 & 19.816 & 0.527 \\
\hline
\end{tabular}


Table 3. Antibacterial and Antifungal Activity of the NPs Evaluated by the HalfMinimal Inhibitory Concentration ( $\left.\mathrm{IC}_{50}\right)(\mu \mathrm{g} / \mathrm{mL})$.
E. coli
B. subtilis
S. cerevisiae

Sample $\mathrm{IC}_{50}(\mu \mathrm{g} / \mathrm{mL})$

\begin{tabular}{llll}
\hline CuFe@PEG8000(M3) & $6.3 \pm 0.52$ & $7.8 \pm 0.63$ & $34.34 \pm 2.32$ \\
CuFe@TEG(M2) & $9.8 \pm 0.61$ & $8.1 \pm 0.9$ & $82 \pm 1.34$ \\
CuFe@PG(M1) & $7.9 \pm 0.64$ & $9.2 \pm 1.63$ & $98.9 \pm 1.13$ \\
Cu@PEG8000 & $12.28 \pm 0.57$ & $10.92 \pm 0.85$ & $63 \pm 1.72$
\end{tabular}

Note: Values are mean of three replicates along with SD error. All values were found statistically significant, $\mathrm{p} \leq 0.01(* *)$.

Table 4. Cell viability (\%) of fungal cultures incubated for $5 \mathrm{~h}$ with suspensions containing 6, 12.5, 25, 50 and $100 \mu \mathrm{g} / \mathrm{mL}$ of CuFe@PEG8000 (M3) NPs.

\begin{tabular}{|l|l|l|l|l|l|l|}
\hline $\begin{array}{l}\text { Conc. of } \\
\text { M3 NPs }\end{array}$ & $\begin{array}{l}0 \mu \mathrm{g} / \mathrm{ml} \\
\text { Control }\end{array}$ & $6 \mu \mathrm{g} / \mathrm{ml}$ & $12.5 \mu \mathrm{g} / \mathrm{ml}$ & $25 \mu \mathrm{g} / \mathrm{ml}$ & $50 \mu \mathrm{g} / \mathrm{ml}$ & $100 \mu \mathrm{g} / \mathrm{ml}$ \\
\hline $\begin{array}{l}\text { Cell } \\
\text { viability }\end{array}$ & $100 \%$ & $79 \%$ & $75 \%$ & $42 \%$ & $21 \%$ & $16 \%$ \\
\hline
\end{tabular}

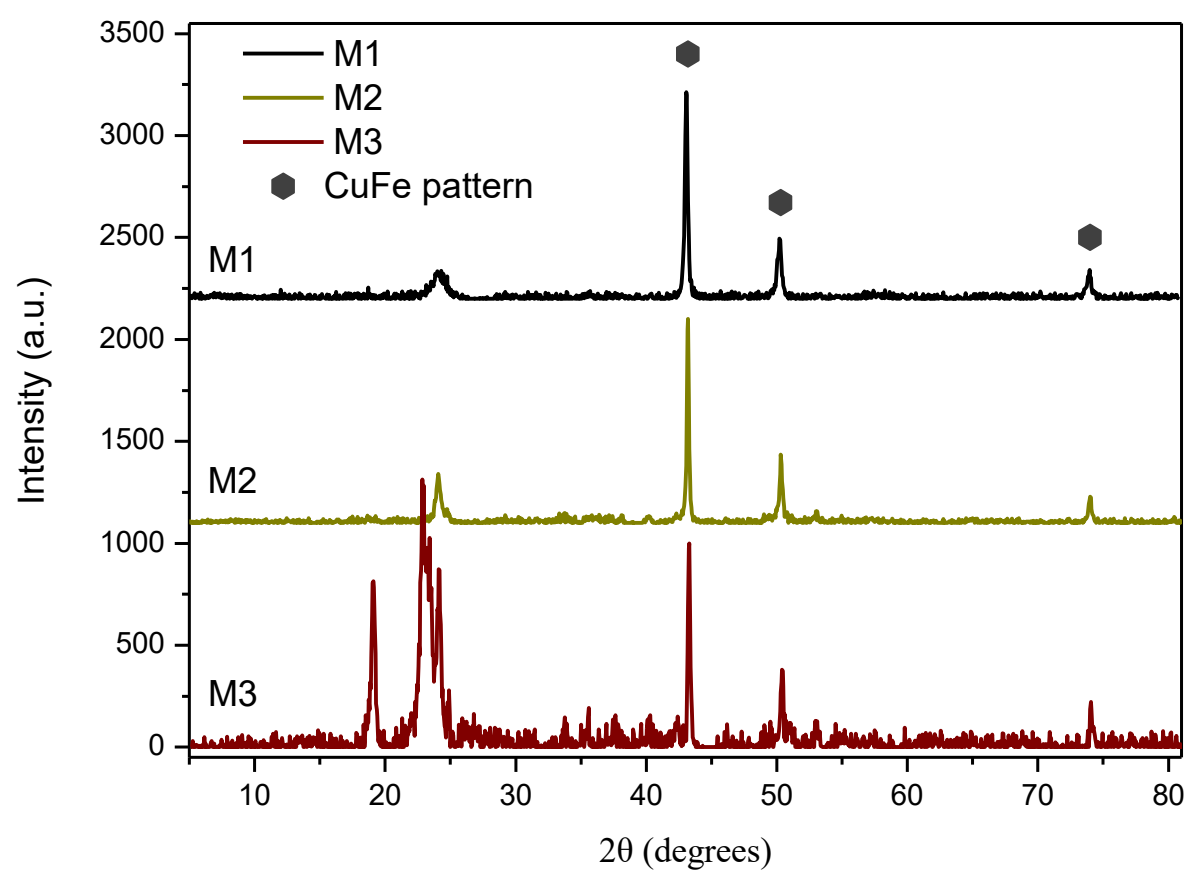

Fig.1 XRD patterns (10-80 degrees) for samples M1-M3. 


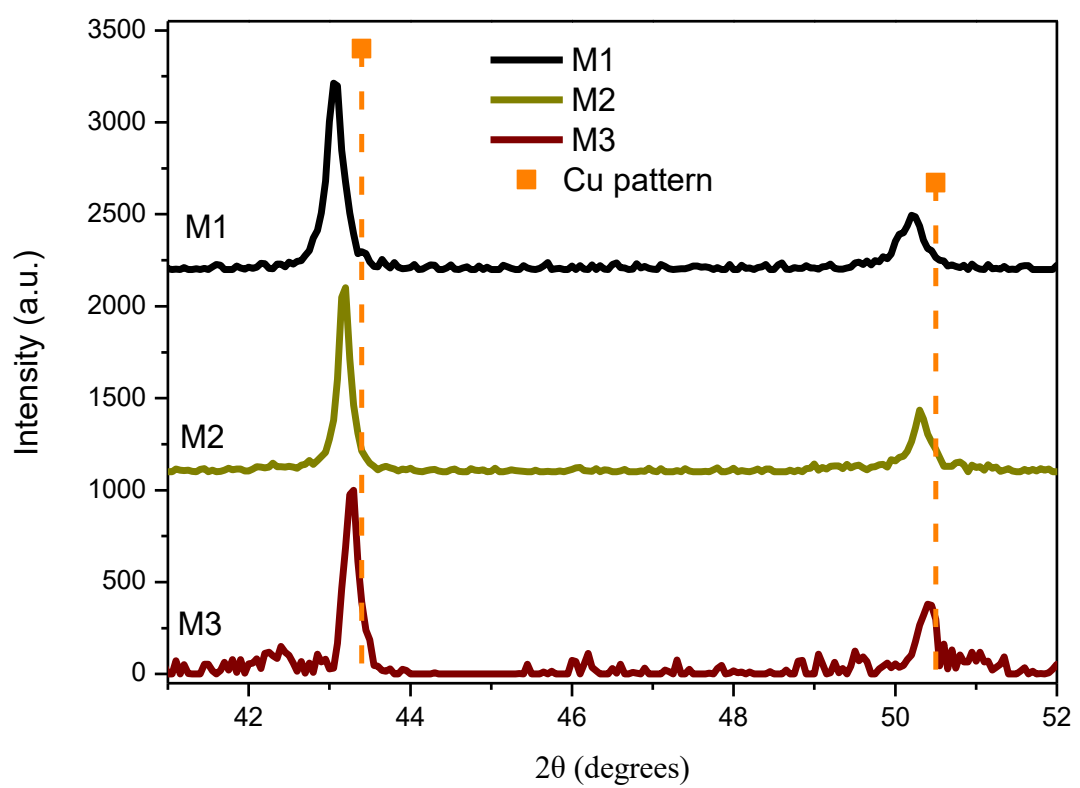

Fig.2 XRD patterns (41-52 degrees) for samples M1-M3. 

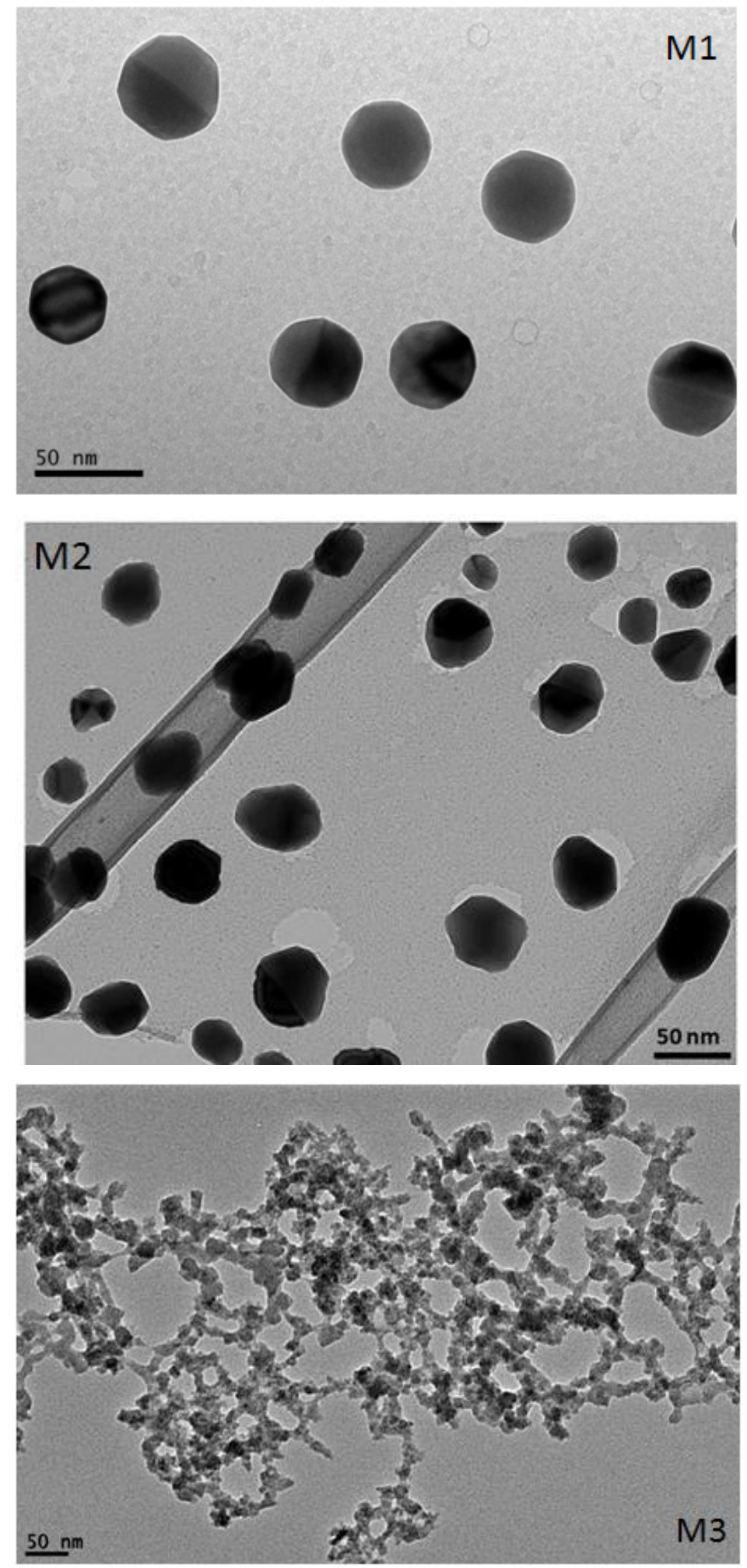

Fig. 3 Representative TEM images of the samples M1-M3. 

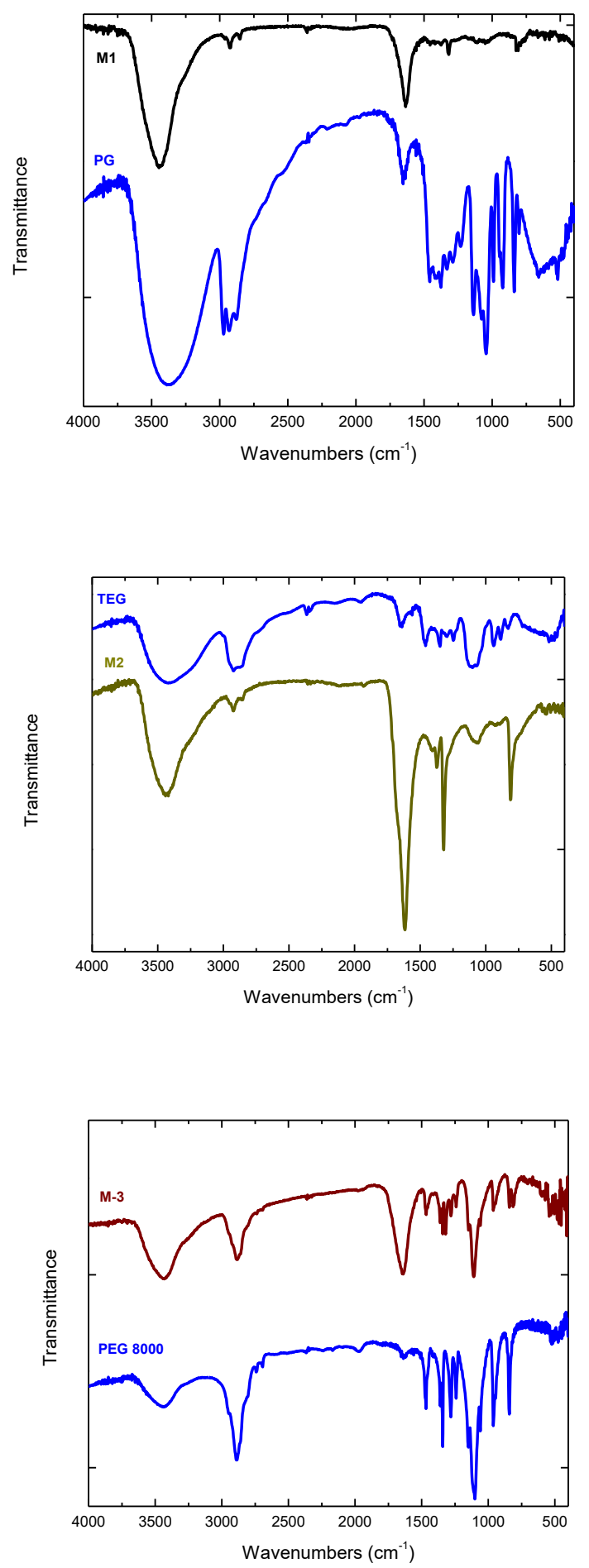

Fig. 4 FTIR spectra of the samples and pure polyols. 


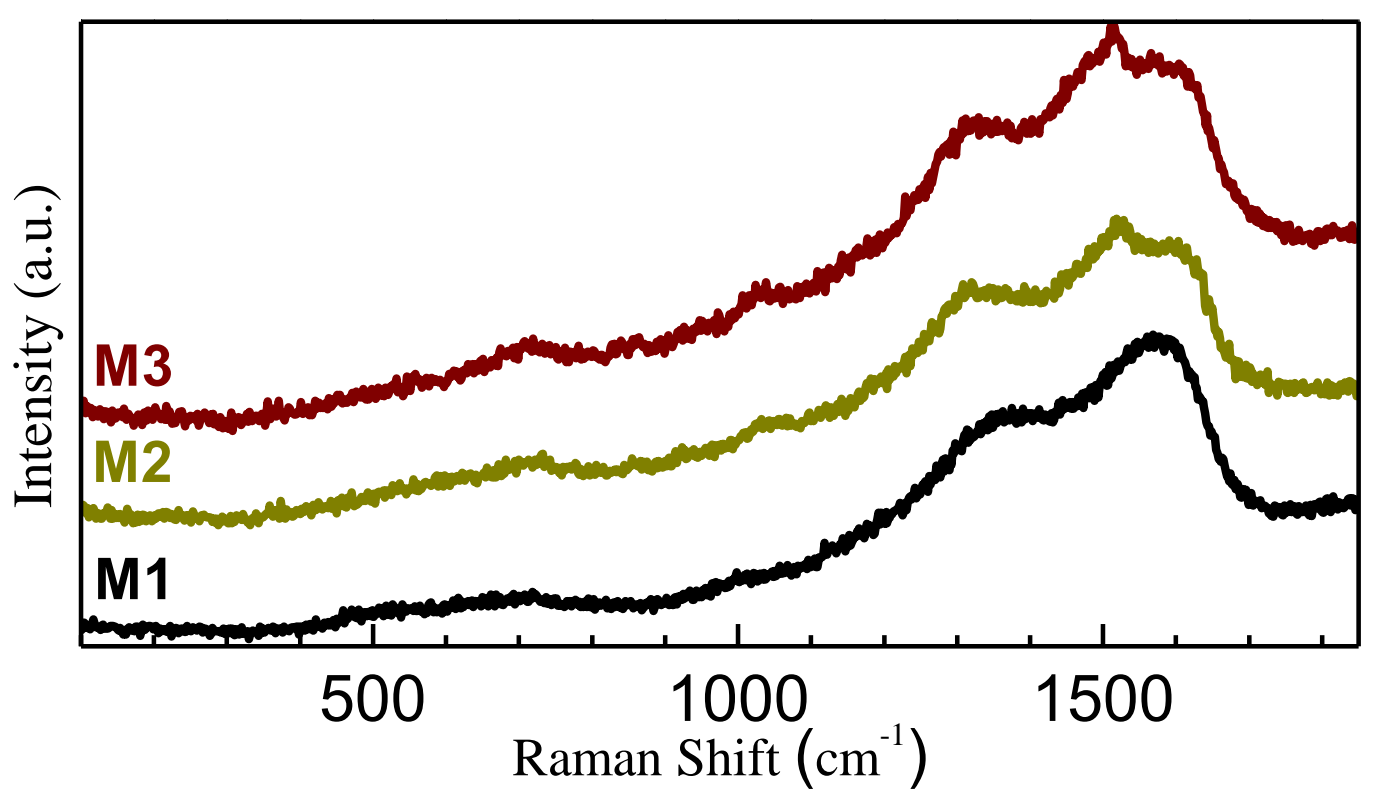

Fig. 5 Raman spectra of the samples.

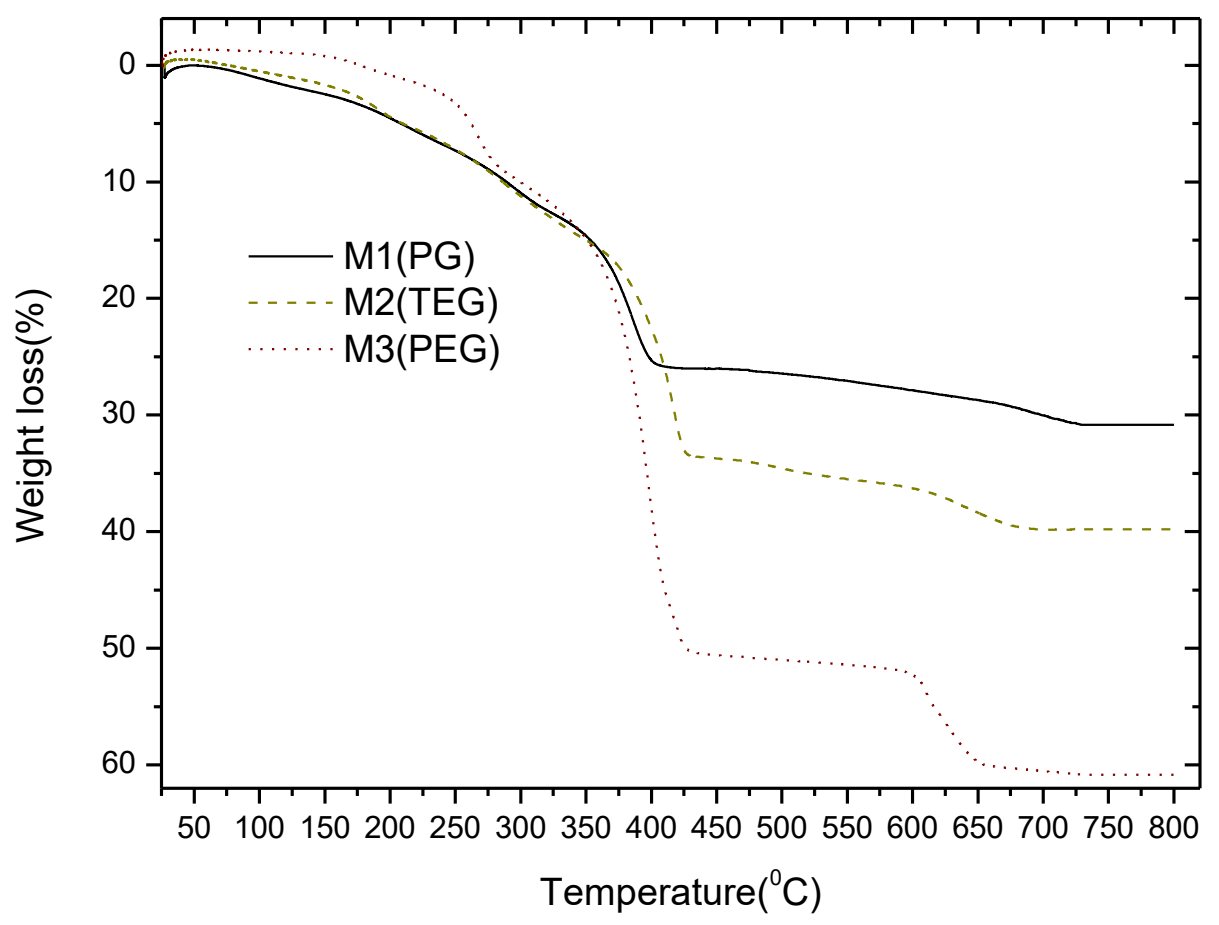

Fig.6 Thermogravimetric curves of the samples M1-M3 showing the relative weight loss attributed to the surfactant removal. 

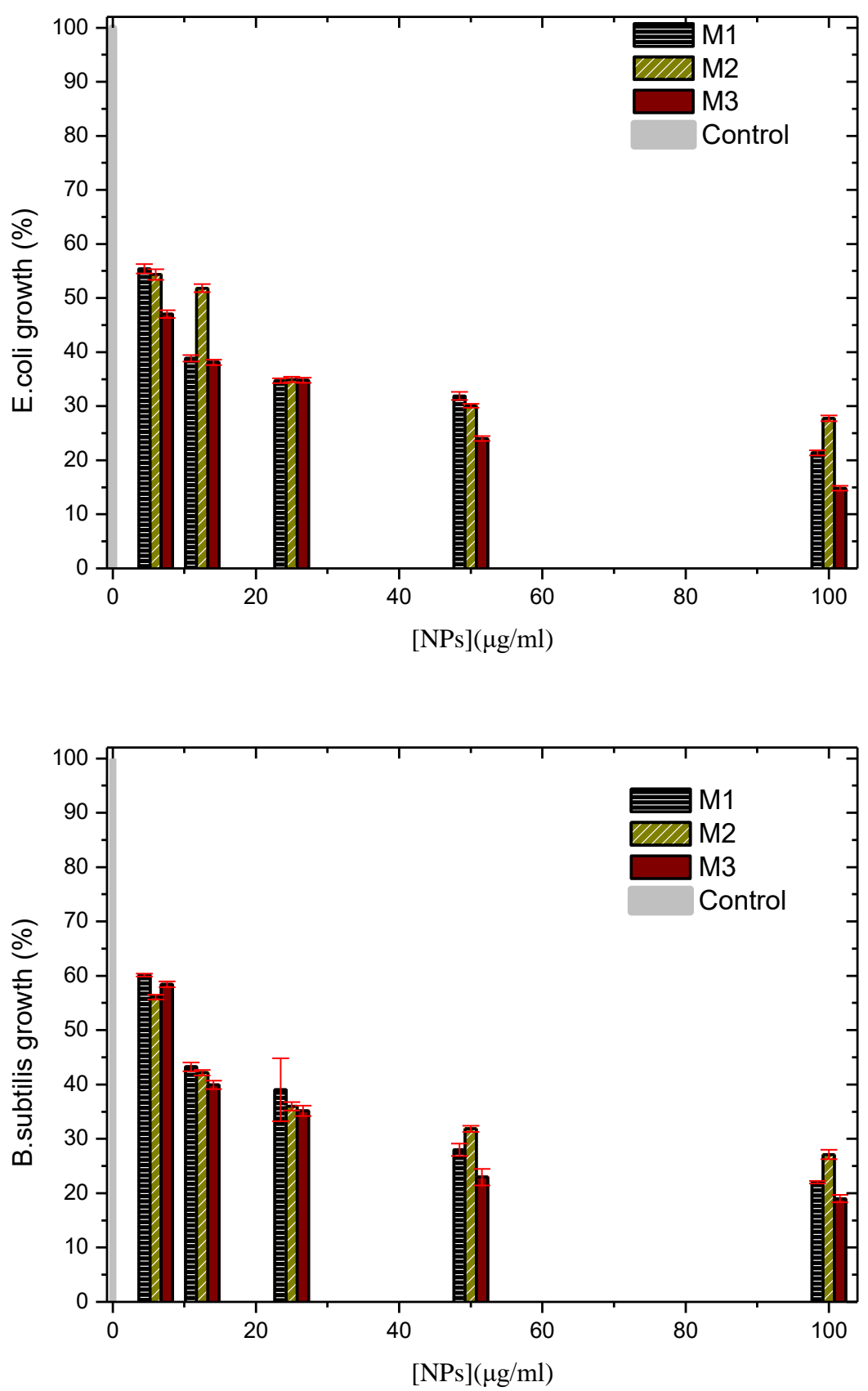


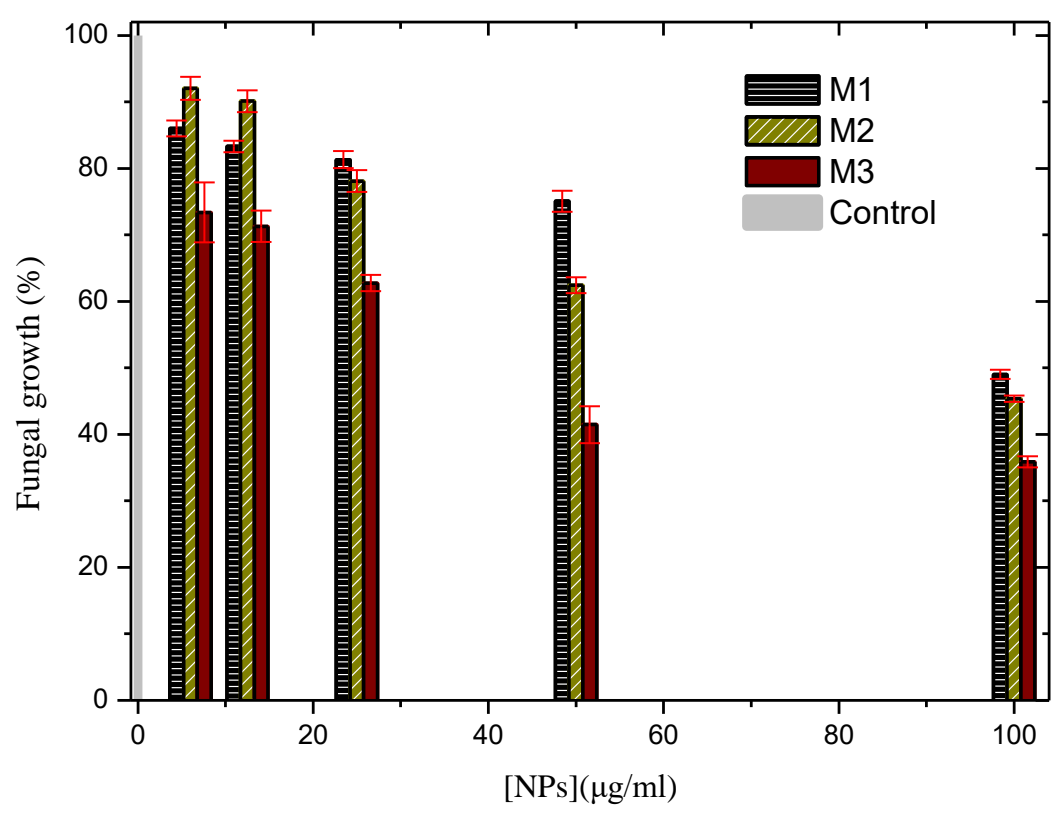

Fig.7. E. coli, B. subtilis and S. cerevisiae growth inhibition (\%) estimated by optical density measurements, $5 \mathrm{~h}$ after the incubation of bacterial and fungal cultures with 6 , 12.5, 25, 50 and $100 \mu \mathrm{g} / \mathrm{mL}$ of CuFe@PG (M1), CuFe@TEG (M2) and CuFe@PEG8000 (M3) NPs. Values are mean of three replicates along with SD error bars.

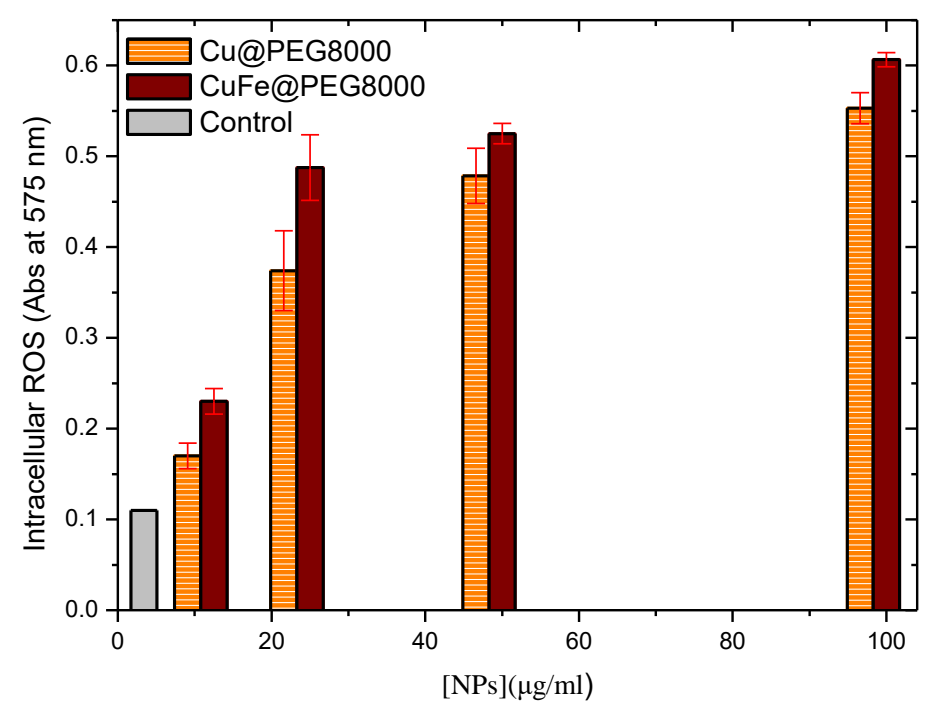

Fig.8. Intracellular $\mathrm{O}_{2}{ }^{-}$generated by Cu@PEG8000 and CuFe@PEG8000 NPs (12.5, 25, 50 and $100 \mu \mathrm{g} / \mathrm{mL}$ of NPs, respectively) detected by the NBT assay. Values are mean of three replicates along with SD error bars. 


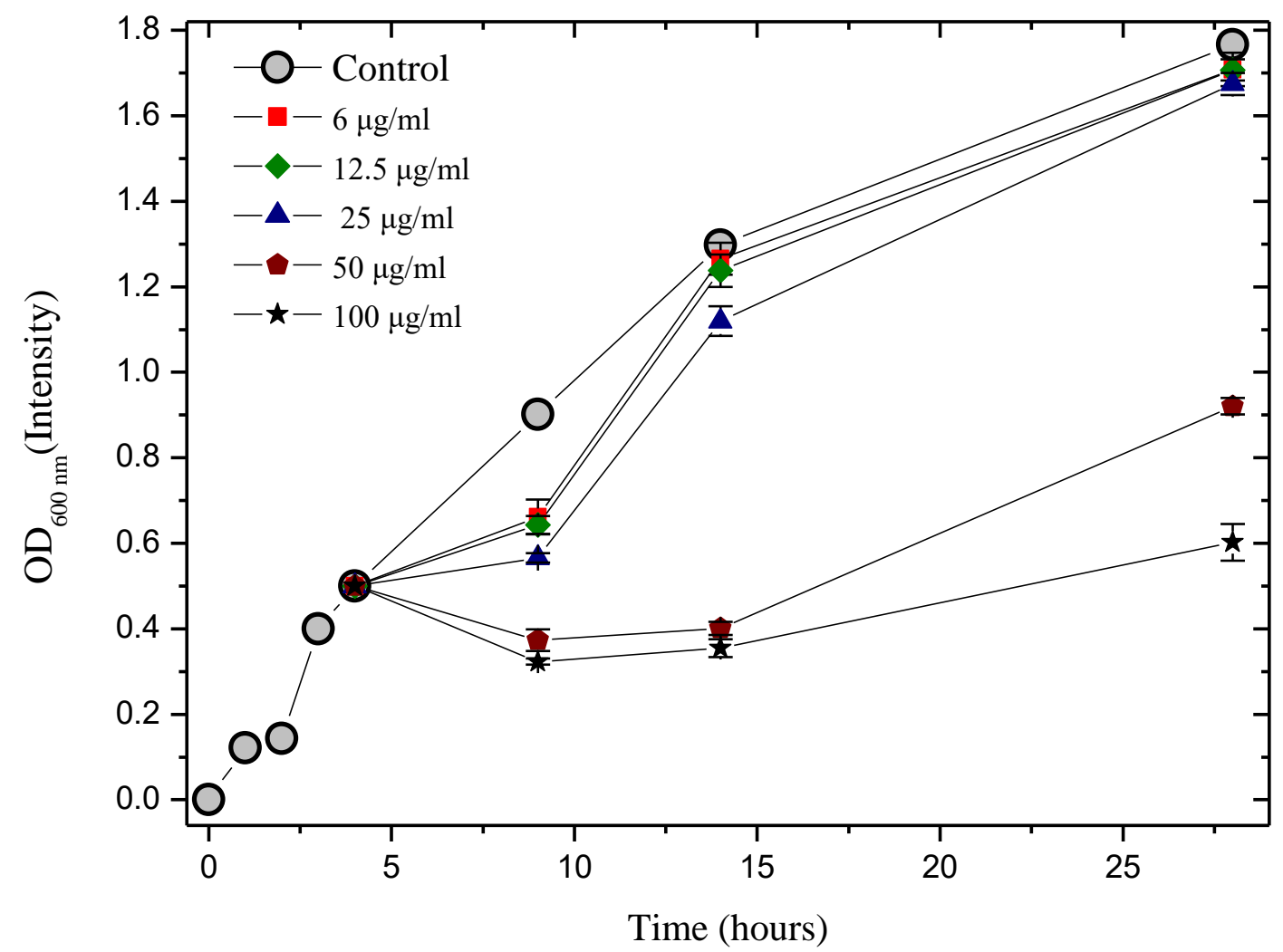

Fig.9. S. cerevisiae growth inhibition curves resulting from optical density measurements carried out for $28 \mathrm{~h}$ in the presence of NPs. Suspensions containing 6, 12.5, 25, 50 and $100 \mu \mathrm{g} / \mathrm{ml}$ of CuFe@PEG8000 (M3) NPs were injected in fungal cultures at the $4^{\text {th }}$ hour of growth. Values are mean of three replicates along with SD error bars. 

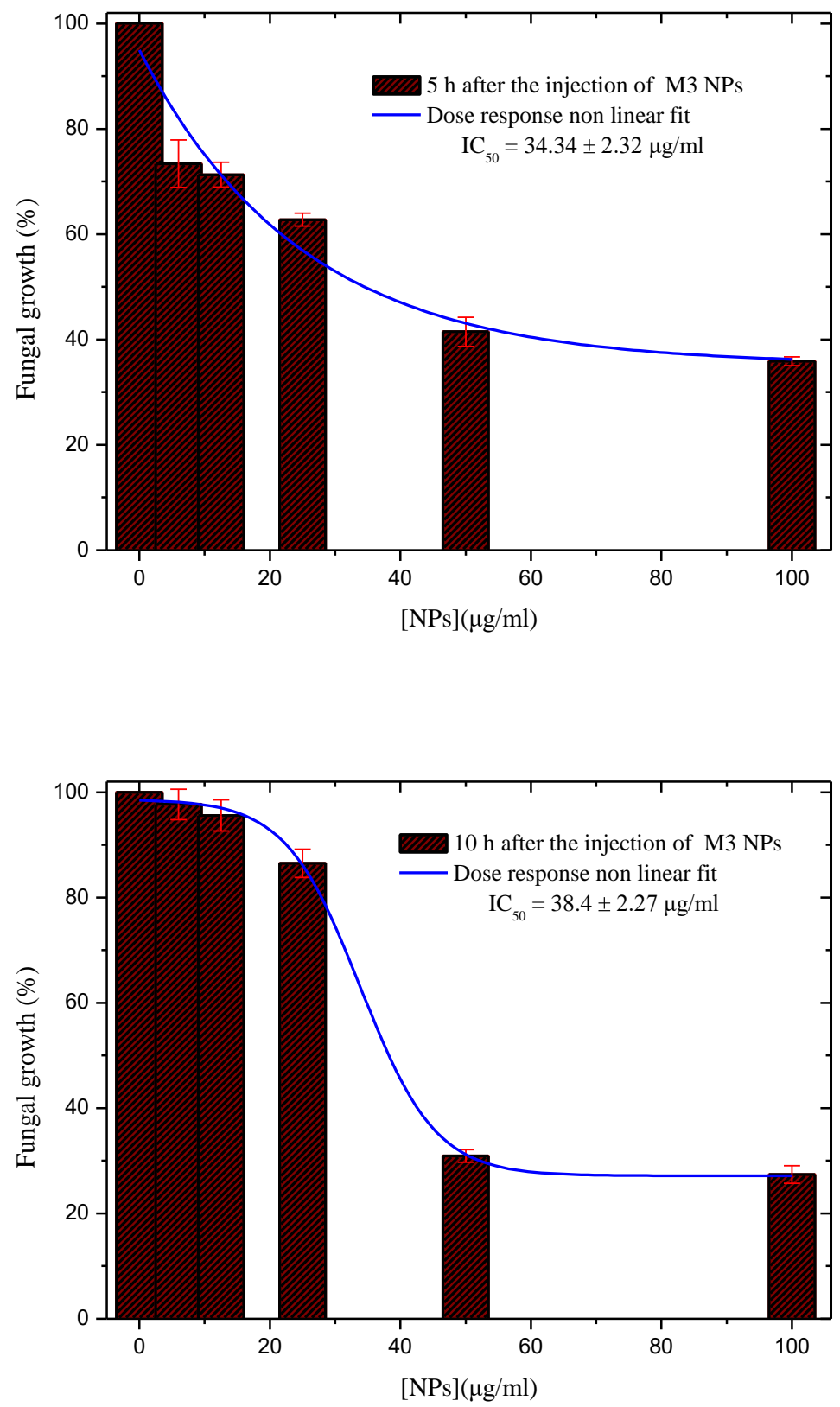


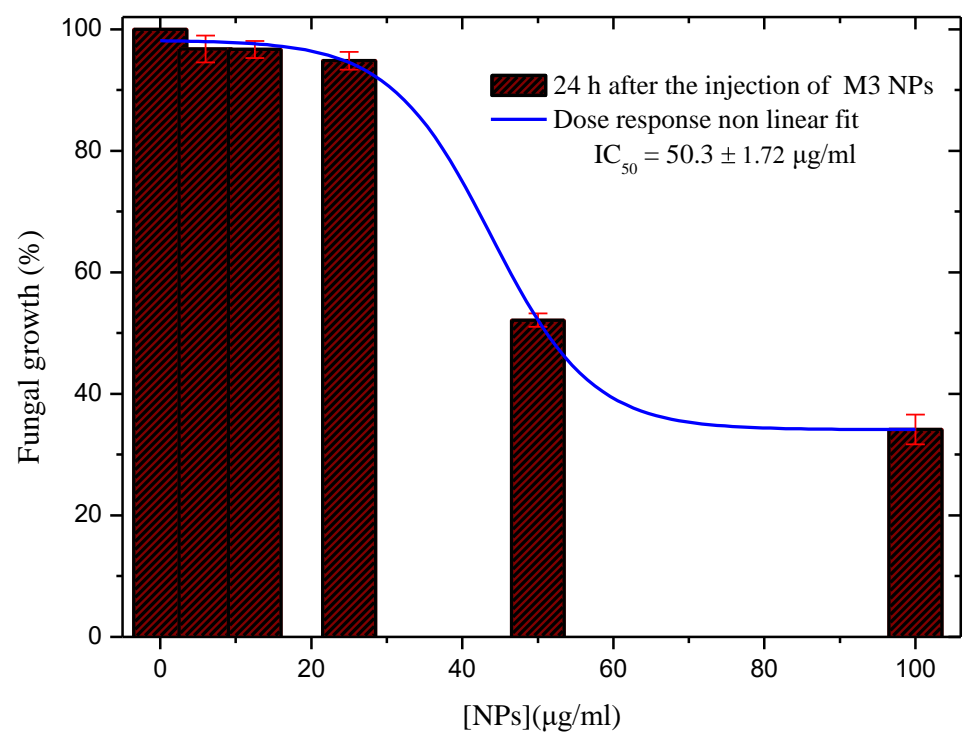

Fig.10. S. cerevisiae growth inhibition (\%) and $\mathrm{IC}_{50}$ values estimated by optical density measurements, 5, 10 and $24 \mathrm{~h}$ after the incubation of M3 NPs in the fungal cultures. Values are mean of three replicates along with SD error bars.

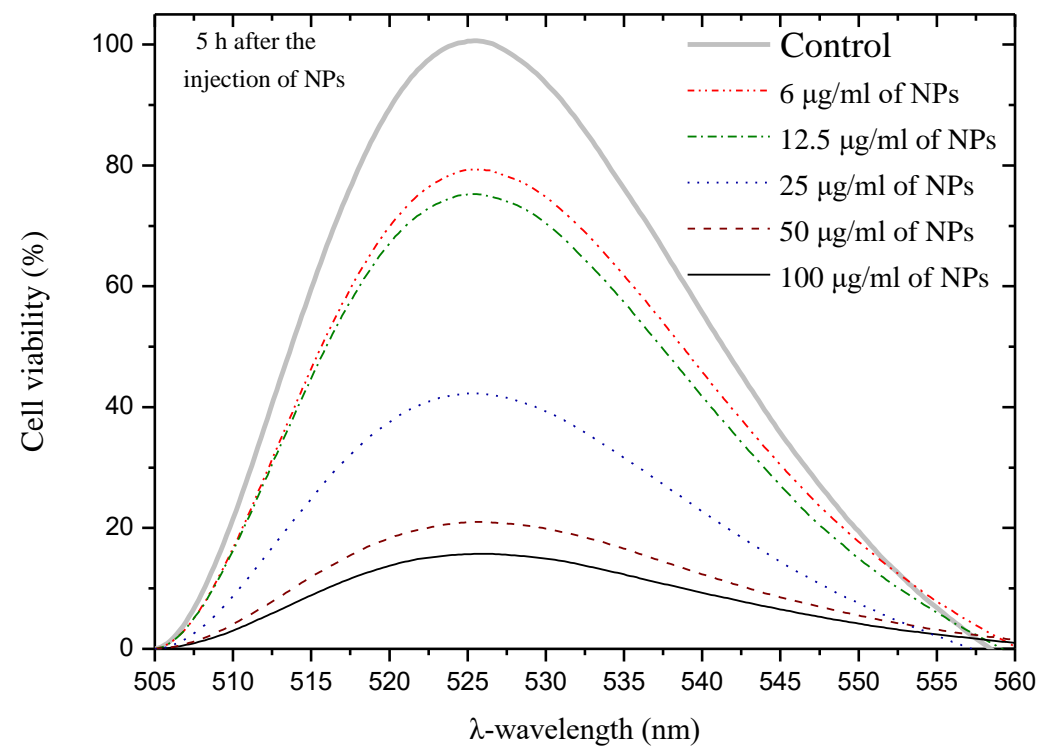

Fig.11. Viability of S. cerevisiae cells (\%) in the presence of 6, 12.5, 25, 50 and 100 $\mu \mathrm{g} / \mathrm{mL}$ of CuFe@PEG8000 (M3) NPs after a 5 h incubation period. The aliquots were excited at $\lambda_{\mathrm{exc}}=495 \mathrm{~nm}$ and the fluorescence was measured at $\lambda_{\mathrm{em}}=525 \mathrm{~nm}$, with excitation and emission slits set at $2.5 \mathrm{~nm}$. 


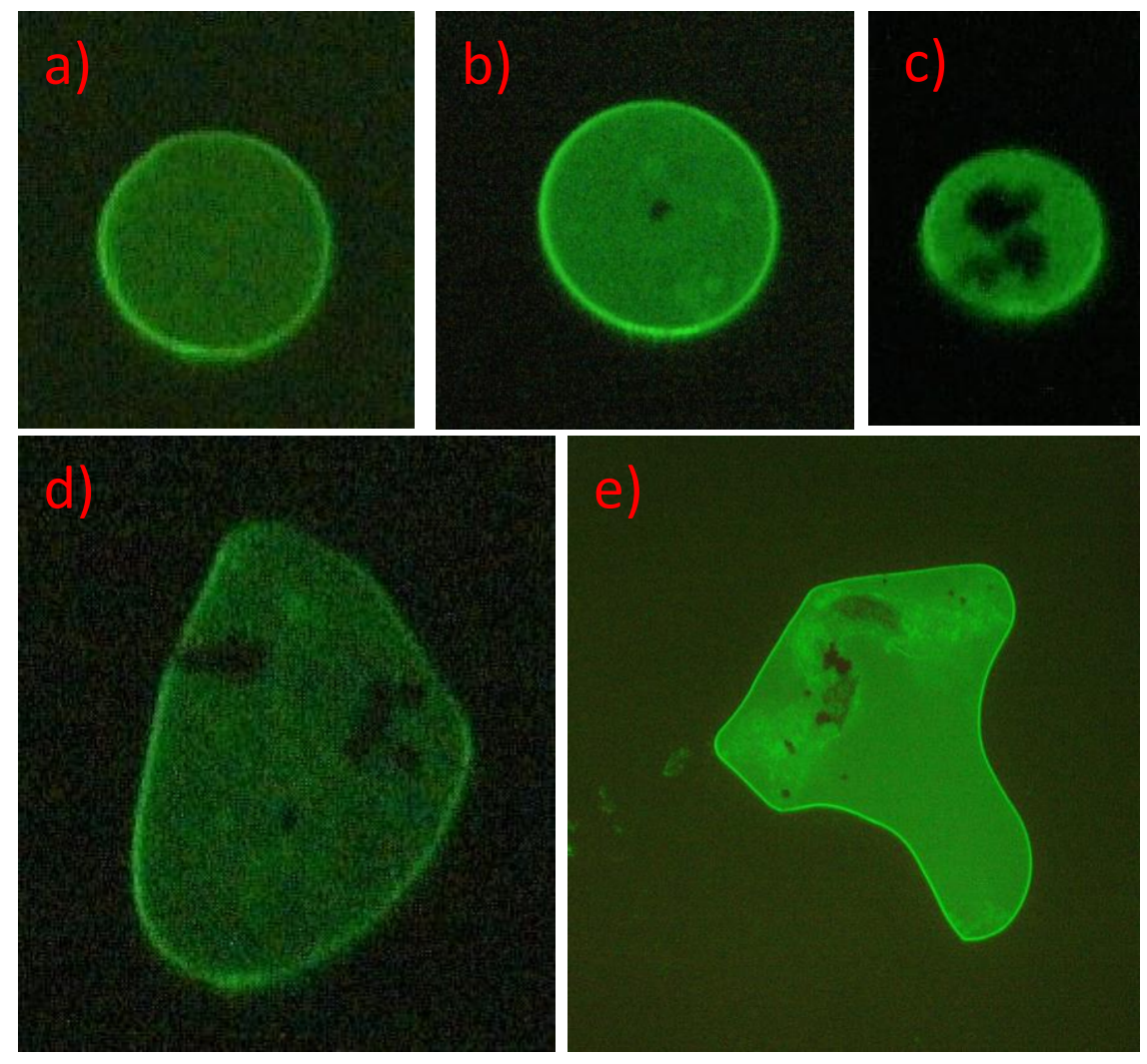

Fig.12. Optical fluorescence microscopy images (high magnification(40x)) of $S$. cerevisiae cells in the absence of NPs (control)(a), in the presence of CuFe@PG (M1) NPs(b), CuFe@TEG (M2) NPs(c) and CuFe@PEG 8000 (M3) NPs(d \& e). 